\title{
The Effects of Derivatives on Firm Risk and Value
}

\author{
Söhnke M. Bartram, Gregory W. Brown, and Jennifer Conrad*
}

\begin{abstract}
Using a large sample of nonfinancial firms from 47 countries, we examine the effect of derivative use on firm risk and value. We control for endogeneity by matching users and nonusers on the basis of their propensity to use derivatives. We also use a new technique to estimate the effect of omitted variable bias on our inferences. We find strong evidence that the use of financial derivatives reduces both total risk and systematic risk. The effect of derivative use on firm value is positive but more sensitive to endogeneity and omitted variable concerns. However, using derivatives is associated with significantly higher value, abnormal returns, and larger profits during the economic downturn in 2001-2002, suggesting that firms are hedging downside risk.
\end{abstract}

\section{Introduction}

Derivatives are financial weapons of mass destruction.

—Warren E. Buffett, 2003 Berkshire Hathaway Annual Report

The financial crisis of 2008-2009 has brought new scrutiny to the use of financial derivatives. Recent proposals in major countries, including the United States, call for greater regulation of over-the-counter (OTC) derivatives, including conditions for marking positions to market prices, trade registration, trade clearing, exchange trading, and higher capital and margin requirements.

\footnotetext{
*Bartram, s.m.bartram@lancaster.ac.uk, Lancaster University, Management School, Lancaster LA1 4YX, United Kingdom, and State Street Global Advisors; Brown, gregwbrown@unc.edu, Conrad, j_conrad@unc.edu, Kenan-Flagler Business School, University of North Carolina at Chapel Hill, CB 3490, Chapel Hill, NC 27599. We thank Hendrik Bessembinder (the editor), Evgenia Golubeva, Reint Gropp, Peter Pope, Peter Tufano (the referee), Gautam Vora, Tracy Yue Wang, Chu Zhang, and seminar participants at the 2009 Meetings of the Western Finance Association, 18th Annual Conference on Financial Economics and Accounting, 2006 Financial Intermediation Research Society Conference, 2007 Meetings of the Financial Management Association, DePaul University, Exeter University, Florida State University, Georgia State University, Göttingen University, Hamburg University, Manchester University, Münster University, Regensburg University, State Street Global Advisors, University of North Carolina at Chapel Hill, and York University for helpful comments and suggestions. Financial support by the Leverhulme Trust is gratefully acknowledged. Bartram gratefully acknowledges the warm hospitality of the Kenan-Flagler Business School of the University of North Carolina, and the Red McCombs School of Business, University of Texas at Austin, during visits to these institutions.
} 
The derivative securities that have caused the most harm during this economic downturn have been those held by financial firms. In contrast, there have been relatively few instances of problems with derivatives at nonfinancial firms in the current downturn. ${ }^{1}$ As a consequence, in response to the proposed new regulations of derivatives, many nonfinancial firms in the U.S. (including energy producers, airlines, and industrial equipment manufacturers) have started lobbying Congress, arguing that the proposed rule changes may "drive U.S. companies to seek financing overseas, ... . [impair firms' ability to] manage fluctuations in materials prices, commodities, fuel, interest rates, and foreign currency," and, in general, materially harm the $90 \%$ of Fortune 500 companies that use financial derivatives to manage risk. ${ }^{2}$

In fact, although data on derivatives usage have become available in the last 2 decades, detailed empirical evidence on the effects of derivative use on firms' risk and value is still mixed. For example, using a sample of firms that initiate derivative use, Guay (1999) finds that the total risk, idiosyncratic risk, and risk exposures to interest rate changes of these firms decline, but he finds no significant change in the market risk of these firms. In contrast, Hentschel and Kothari (2001) find that the difference in risk for firms that use derivatives is economically small compared to firms that do not use them. Allayannis and Weston (2001) present evidence that hedging foreign currency risk is associated with large (approximately $4 \%$ ) increases in market value; Graham and Rogers (2002) find that hedging can add an economically significant $1.1 \%$ to firms' market value by allowing firms to increase their debt capacity. However, Guay and Kothari (2003) show that the magnitude of the cash flows generated by hedge portfolios is modest and unlikely to account for such large changes in value. Consistent with this, Jin and Jorion (2006) use a sample of oil and gas producers and find insignificant effects of hedging on market value.

In this paper, we also examine the effect of derivative use on firms' risk and market values. We use a new, larger data set that includes 6,888 nonfinancial firms headquartered in 47 different countries. In addition to providing greater statistical power for our tests, our data set covers a wide range of derivative use and risk measures. Specifically, we investigate the impact of the use of exchange rate (FX), interest rate (IR), and commodity price (CP) derivatives on cash flow volatility, the standard deviation of stock returns, and market betas, as well as market values. The data set also allows us to measure the effect of derivative use on firms during a sample period that includes a sharp market correction: the global recession of 2001. Consequently, we are able to examine the extent to which firms, either through their use of derivative contracts or other methods (e.g., operational hedges), can mitigate a marketwide decline. Evidence on whether derivative use

\footnotetext{
${ }^{1}$ The exception is a series of significant losses among some Brazilian and Mexican nonfinancial companies that appear to have undertaken speculative currency trades that went bad in 2008 as local currencies depreciated rapidly against major currencies, especially the U.S. dollar. The relative paucity of problems in 2008-2009 among nonfinancial firms may be due to the fact that, following systematic problems arising from losses involving derivatives among nonfinancial firms in the early 1990s, many large nonfinancial corporations adopted strict risk management policies for hedging with derivatives.

${ }^{2}$ See "Big Companies Go to Washington to Fight Regulations on Fancy Derivatives," by Kara Scannell, The Wall Street Journal (July 10, 2009, p. B1).
} 
can provide protection against systematic declines for some firms is particularly useful when the costs and benefits of additional regulation on these markets is being considered.

Figure 1 provides some insights into our primary findings by plotting the time series of cumulative returns, volatility, and market betas for portfolios of derivative users and nonusers from 1998 through the end of 2003. These results

\section{FIGURE 1}

\section{Cumulative Returns of Users and Nonusers}

Figure 1 shows various characteristics of (U.S. dollar) market-value weighted portfolios of derivative users and nonusers from 1998 through 2003. Graph A plots cumulative returns for the portfolios of users (dashed line) and nonusers (solid line) as well as the world market index. Graph B plots the annualized standard deviation (volatility) of each portfolio calculated using a rolling 3-month window. Graph C plots market betas of each portfolio calculated using a rolling 3-month window. A derivative user is defined as a firm using any type of derivative in 2000 or 2001 . The indices are constructed using daily returns obtained from averaging returns each day for all firms with available return data. Returns are measured in local currency. In Graph A, both users and nonusers outperform the world market index because we exclude financial firms and utilities that significantly underperform other stocks over this period.

Graph A. Cumulative Abnormal Returns

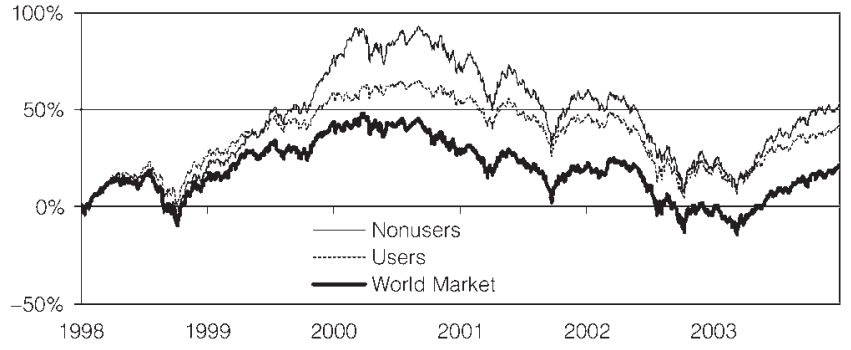

Graph B. Volatilities

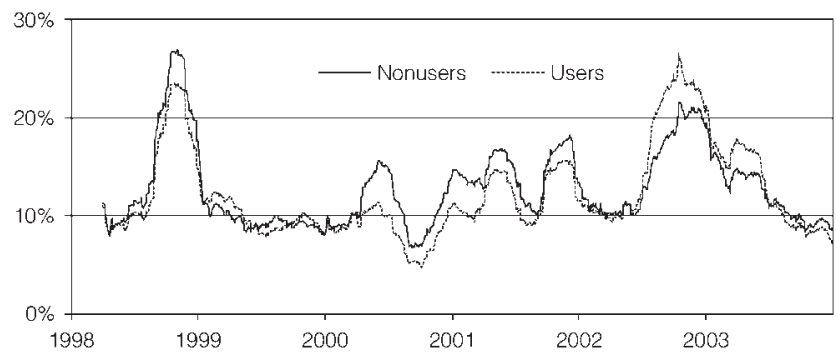

Graph C. Portfolio Betas

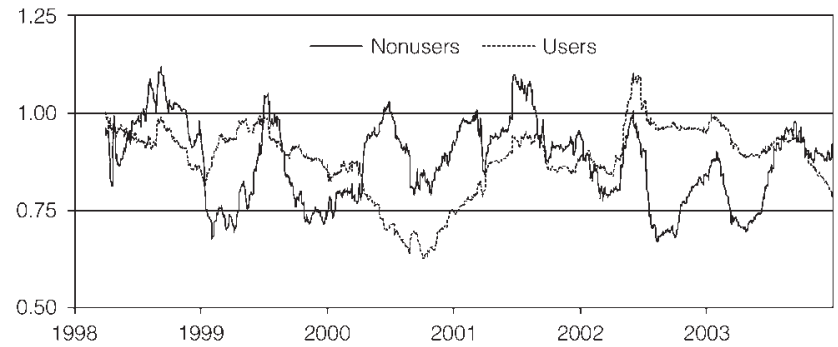


must be interpreted with caution, since we do not account for the firm-level differences between users and nonusers; however, they are indicative of our results. Graph A shows that during the 2000-2001 period, users' returns seem to increase and decrease less than those of nonusers. These return patterns suggest that users may be on average less volatile and have lower market betas than those of nonusers. To examine this more directly, Graph B plots volatilities of users and nonusers for 3-month rolling windows over the same period. The plots show that users tend to have lower volatility, especially during the bear market from 2000 to 2002. ${ }^{3}$ Graph C plots estimates of market betas also calculated from 3-month rolling windows. While the average betas of the portfolios are about the same, the portfolio of users tends to have a lower beta during down markets.

The evidence in Figure 1 suggests that, at the aggregate level, firms that use derivatives may do so to reduce risk, and particularly to reduce the risk of down markets. At the firm level we also obtain results suggesting that firms use derivatives to reduce risk. Users of derivatives are more exposed to exchange rate risk (due to more foreign sales, foreign income, and foreign assets) and interest rate risk (due to higher leverage and lower quick ratios) before considering the potential effects of risk management with derivatives. They are also more likely to belong to commodity-based industries that are exposed to commodity price risk. Nonetheless, derivative users exhibit unconditional average cash flow volatility that is almost $50 \%$ lower than that of nonusers and stock return volatility that is on average $18 \%$ lower than the return volatility of nonusers. In addition, firms that use derivatives have market betas that are on average $6 \%$ lower than those of nonusers. Consistent with other papers, we also find that, on average, derivative users tend to be larger and older firms. Consequently, the unadjusted Tobin's $q$ of the average derivative user is approximately $17 \%$ lower than that of the average firm that does not use derivatives.

One factor that affects the interpretation of these results, and may generate some of the differences across studies, is endogeneity. That is, a significant difference in the risk measures of firms that use, or do not use, derivatives could be due to omitted control variables that determine firm risk and risk management practices; alternatively, omitting these variables may mask important differences among firms that arise because of differences in hedging behavior. Endogeneity also affects the interpretation of results: Derivative use may be driven by, rather than a determinant of, differences in risk. As a result, riskier firms may use derivatives so that their (after-hedging) risk profile is indistinguishable from inherently less risky nonusers. The papers cited previously use different approaches to control for endogeneity. Some authors use econometric procedures such as simultaneous equations to account for this problem (see, e.g., Graham and Rogers (2002)). Others choose samples to mitigate selection bias. Jin and Jorion (2006), for example, control for any significant difference in the hedging propensity of firms across industries by examining firms in a single industry. By examining only firms that

\footnotetext{
${ }^{3}$ In fact, average volatilities for the portfolio of users is $0.5 \%$ lower than for nonusers. When we split the sample into bear-market (April 1, 2000-December 31, 2002) and bull-market (all other dates) periods, we find that users have lower volatility in both periods, but the difference is greater during the bear-market period. Specifically, volatilities go up for both groups, but by twice as much for nonusers.
} 
initiate derivative use, Guay (1999) uses the same firm prior to derivative use as a control. Of course, although these choices reduce selection bias, they also impose constraints on the data beyond the usual ones of data availability.

In multivariate tests, we control for the endogenous nature of the decision to use derivatives using a propensity score matching technique; in addition, we are able to provide some evidence for how large any remaining hidden bias would have to be to change inferences drawn from our analysis. Propensity score matching allows us to match firms on the basis of their estimated likelihood of using derivatives, rather than matching on a large number of individual firm characteristics. Specifically, using a binary variable to measure derivative use, we directly estimate firms' propensity to use derivatives based on their characteristics, and then we match firms that use derivatives to those firms that do not use derivatives, based on this propensity. Controlling for firms' likelihood to use derivatives, we find that derivative use is associated with lower cash flow volatility, lower standard deviation of returns, lower systematic risk, and weakly higher market values. Derivative users have 7\%-18\% lower cash flow volatility, 5\%-10\% lower standard deviation of returns, and $15 \%-31 \%$ lower betas than matching firms that do not use derivatives, depending on the set of characteristics used to estimate the propensity to hedge. ${ }^{4}$ We also find higher Tobin's $q$ for derivative users, although the differences are not always statistically significant.

As mentioned previously, any analysis of cross-sectional differences in firm characteristics related to derivative use must be concerned about endogeneity or bias due to an omitted control variable. Using a relatively new technique, we are able to estimate the extent to which our inferences may be driven by a hidden selection bias. Specifically, using the method developed in Rosenbaum (2002), we find that for a hidden selection bias related to an unobserved characteristic to affect our inferences regarding the effect of derivative use on risk, it would have to be large (e.g., equivalent to approximately a 2-standard-deviation difference in leverage or more than a doubling in market capitalization). Thus, while we cannot rule out the possibility that our risk results are driven by an unmeasured selection bias in our sample, the unmeasured characteristics related to that selection bias would generally have to be quite economically significant (as well as unrelated to the large number of observables for which we control). In contrast, the results with respect to value appear to be quite sensitive to the presence of a hidden selection bias. In turn, this sensitivity could explain why value results from previous studies are mixed. Overall, our results suggest that the effect of derivative use in the cross section is associated with a decline in both total and systematic risk; the effect on value is positive, but weaker.

We also examine the differences in risk and value measures associated with derivative use through time. Firms that use derivatives have consistently lower total risk and betas throughout the 1998-2003 sample period. However, the results provide evidence that using derivatives is more important for firm value during the global economic decline in 2001. This may be because of a change in the (perceived) value of risk management, with the relative value of firms that

\footnotetext{
${ }^{4}$ Results for cash flow volatility, total risk, and market risk are always statistically significant at better than the $0.1 \%$ level.
} 
use derivatives increasing during an economic decline. Alternatively, these results may simply reflect the unstable nature of the value results. However, when we examine average alphas (from the market-model regressions that generate market betas), we also find that firms that use derivatives significantly outperform firms that do not use derivatives during this period. In addition, profit measures of derivative users, whether measured as earnings, cash flow, or return on assets (ROA), are consistently higher than those of firms that do not use derivatives during 2000-2002 (as opposed to 1998, 1999, and 2003, when the differences are not as consistently large or significant).

We perform additional analysis on the relation between derivative use, risk, and financial distress. We find evidence that firms that use derivatives tend to have lower $Z$-scores, but similar expected default probabilities. This suggests that firms that use derivatives for financial risk management may be able to increase other risks (for which they may get compensated) without an overall increase in the chance of financial distress. We also examine whether the effects of derivative use on risk differ by derivative type, or by firms' access to derivative markets. We find little evidence that derivative type matters. We find some evidence that a portion of the benefits of derivative use decline with reduced access; in particular, the reduction in cash flow volatility is mitigated if firms have poorer access to derivative markets.

Our results suggest, at a minimum, that firms reduce cash flow risk, total risk, and systematic risk significantly through financial risk management with derivatives. This result is robust to controlling for differences in a large number of firm characteristics, as well as differences in country and industry. Thus, while it may be difficult to preclude all instances of improper or fraudulent use of derivative instruments, these findings can provide some reassurance to policymakers, regulators, and shareholders (or other stakeholders in the firm, for that matter), who are concerned that widespread derivatives speculation by nonfinancial corporations puts the firm at greater risk. The effect on market value associated with this risk reduction, however, is less certain.

\section{Frequency and Effect of Derivative Use by Firms}

Beginning with Modigliani and Miller (MM) (1958), a firm managed by value-maximizing agents, in a world of perfect capital markets, with investors who have equal access to these markets, would not engage in hedging activities, since they add no value. Anything the firm could accomplish through hedging could equally well be accomplished by the investor acting on his or her own account. If the perfect capital markets assumption is not met, however, there may be rational reasons for the firm to hedge.

The theoretical literature on hedging relaxes the MM (1958) assumptions and develops specific reasons why individual firms may optimally choose to hedge. As one might expect, these reasons tend to involve either market frictions, such as taxes, transactions costs, and informational asymmetries, or agency problems. For example, Smith and Stulz (1985) show that a convex tax function implies that a firm can reduce expected tax liabilities by using hedges to smooth taxable income. In addition, hedging may increase a firm's debt capacity, enabling it to 
add value by increasing the value of the debt tax shield (Leland (1998)). Froot, Scharfstein, and Stein (1993) show that managers facing external financing costs may use hedging to reduce the probability that internal cash flows are insufficient to cover investments; Smith and Stulz show that hedging can reduce expected costs of distress.

Agency problems may cause managers and investors to view the risk-return trade-offs of the firm differently and lead to the use of derivative contracts. For example, if managerial compensation leaves the manager holding a large portfolio of undiversified firm risk, the manager may have a larger incentive to hedge (Stulz (1984)). Alternatively, if a large fraction of managers' compensation comes in the form of out-of-the-money stock options, the manager may have an incentive to use derivatives to take on, rather than lay off, firm risk. DeMarzo and Duffie (1995) argue that hedging may allow investors to assess managers' abilities more precisely and consequently develop more efficient compensation contracts.

Empirically, the use of derivatives by firms appears to be widespread. A large number of studies have documented the extent and nature of derivatives use by nonfinancial firms. Some of these studies are based on survey data, such as the Wharton survey of U.S. nonfinancial firms (Bodnar, Hayt, and Marston (1996), (1998), Bodnar, Hayt, Marston, and Smithson (1995)), as well as other surveys of U.S. firms (e.g., Nance, Smith, and Smithson (1993)). Surveys also have been conducted for selected countries outside the United States. ${ }^{5}$ Studies have provided information on corporate derivatives use based on disclosure in annual reports (Mian (1996), Géczy, Minton, and Schrand (1997), Graham and Smith (1999), and Graham and Rogers (2002)). Finally, detailed data on derivatives use is available for a few industries, such as in the North American gold mining industry (e.g., Tufano (1996), Brown, Crabb, and Haushalter (2006)) or the U.S. oil and gas industry (Haushalter (2000)). Overall, these studies document that the use of derivatives by nonfinancial firms tends to be the rule rather than the exception.

Empirical researchers have used data disclosed by firms to examine the question of whether and how hedging affects the risks of the firm. The evidence is mixed. Guay (1999) investigates a sample of 234 U.S. nonfinancial firms that began using derivatives in the early 1990s and finds that measures of total and idiosyncratic risk declined in the following year. He finds no significant evidence for changes in systematic risk. Hentschel and Kothari (2001) examine the risk characteristics of a panel of 425 large U.S. nonfinancial firms from 1991 to 1993. Their results show no significant relationship between derivatives use and stock return volatility even for firms with large derivatives positions.

In a study of the North American gold mining industry, Tufano (1996) presents evidence that is consistent with the use of derivatives for hedging to reduce risk in response to risk aversion by managers and owners. Allayannis and Ofek (2001) relate derivatives use to the foreign exchange rate exposure of a

\footnotetext{
${ }^{5}$ For example, survey data are available for Belgium (DeCeuster, Durinck, Laveren, and Lodewyckx (2000)), Canada (Downie, McMillan, and Nosal (1996)), Germany (Bodnar and Gebhardt (1999)), Hong Kong and Singapore (Sheedy (2002)), the Netherlands (Bodnar, Jong, and Macrae (2003)), New Zealand (Berkman, Bradbury, and Magan (1997)), Sweden (Alkeback and Hagelin (1999)), Switzerland (Loderer and Pichler (2000)), and the United Kingdom (Grant and Marshall (1997)).
} 
sample of 378 U.S. nonfinancial firms and find that the use of derivatives significantly reduces the exposure of the sample firms to exchange rate risk. In work on mutual funds, Koski and Pontiff (1999) show that users of derivatives have similar risk exposure and return performance to nonusers.

The evidence for the effect of derivative use on market value is also mixed. Allayannis and Weston (2001) find that firm value (as measured by Tobin's $q$ ) is higher for U.S. firms with foreign exchange exposure that use foreign currency derivatives to hedge. ${ }^{6}$ Graham and Rogers (2002) calculate that the increase in debt capacity and leverage associated with hedging increases firm value by an average of about $1.1 \%$. However, Guay and Kothari (2003) estimate the cash flow implications from hedging programs for 234 large U.S. nonfinancial firms and find that the economic significance of the cash flows, and consequently the inferred potential change in market values, is small. Jin and Jorion (2006) examine 119 firms in the oil and gas industry and also find that the effect of hedging on market value is not statistically significant.

Overall, while there is substantial evidence of sustained and growing use of derivatives by firms, the effect of this use on risk and value, and the mechanisms by which value may be affected, are still unclear. Concerns about endogeneity either limit the interpretation of the results or act to limit the sample (see, e.g., Aretz and Bartram (2010)). In an attempt to mitigate these concerns, we use both a larger sample and different methods to control for endogeneity. Our sample includes a large number of U.S. and international firms and encompasses wide swings in global economic conditions, which may create more dispersion in outcomes for users and nonusers of derivatives. We use a matching method that controls for the differences in the likelihood of using derivatives; this method also allows us to conduct additional analyses on the extent to which the results may be sensitive to a remaining hidden selection bias. Finally, we examine the difference in the effects of the global recession of 2000 and 2001 between firms that use derivatives and those that do not.

\section{Data}

\section{A. Sample and Data Sources}

The markets for OTC instruments and exchange-traded derivative financial instruments (options, futures, forwards, swaps, etc.) on foreign exchange rates, interest rates, and commodity prices have exhibited exponential growth over the past 20 years (e.g., Bartram (2000)). As a result, notional amounts outstanding for OTC derivatives reached over $\$ 200$ trillion in 2004, with interest rate derivatives accounting for more than $3 / 4$ of the total (Bank for International Settlements (2005)). Along with increased use, regulation for the disclosure of derivatives has developed, requiring firms in many countries to include information about their derivatives' positions in their annual report. In particular, firms in the United States, United Kingdom, Australia, Canada, and New Zealand as well as firms

\footnotetext{
${ }^{6}$ In related work, Rountree, Weston, and Allayannis (2008) find a negative relation between cash flow volatility and firm value.
} 
complying with International Accounting Standards (IAS) are required to disclose information on their derivatives positions; many other firms do so voluntarily. ${ }^{7}$ The resulting availability of data makes the empirical analysis of the use of derivatives by nonfinancial firms in different countries possible.

The sample in this study comprises 6,888 nonfinancial firms from 47 countries including the United States. It consists of all firms that have accounting data for either the year 2000 or 2001 on the Thomson Analytics database, that have an annual report in English for the same year on the Global Reports database, that are not part of the financial sector (banking, insurance, etc.) or a regulated utility, and that have at least 36 nonmissing daily stock returns on Datastream during the year of the annual report. ${ }^{8}$ The 47 countries represent $99 \%$ of global market capitalization in 2000 and 2001, and the firms in the sample account for $60.6 \%$ of overall global market capitalization or $76.8 \%$ of global market capitalization of nonfinancial firms. ${ }^{9}$

Firms are classified as users or nonusers of derivatives based on a search of their annual reports for information about the use of derivatives. The annual reports are evaluated by an automated search. The list of search terms was compiled by manually analyzing a sample of 200 annual reports across all countries. ${ }^{10}$ After refining the list of search terms, the automated search routine led to an average reliability of $96.0 \%$ for a random sample of annual reports of 100 users and 100 nonusers. Subsequently, an index was created based on search hits of terms that were too general to be included in the electronic search, but that are likely to be related to derivative use. ${ }^{11}$ Since nonusers with high index scores, as well as users with low index scores, are likely to be misclassified, we manually checked the reports of another 1,709 firms based on this index. As a result, the reliability of the classification improved further, yielding an estimated error rate from a random sample of below $2 \% .{ }^{12}$ In addition to the categorical data on derivatives, information on the underlying asset (i.e., foreign exchange, interest rates,

\footnotetext{
${ }^{7}$ For example, the following are recent standards (and effective dates) adopted by so-called G4+1 countries and the International Accounting Standards Board (IASB) as part of the movement toward common reporting standards: United States, FAS 133 (effective June 15, 1999); United Kingdom, FRS 13 (effective March 23, 1999); Australia, AAS 33 (effective January 1, 2000); Canada, AcSB Handbook Section 3860 (Financial Instruments - Disclosure and Presentation, effective January 1, 1996); New Zealand, FRS-31 (effective December 31, 1993); IASB, IAS 32 (March 1995, modified March 1998 to reflect issuance of IAS 39 effective January 1, 2001).

${ }^{8}$ Global reports (www.global-reports.com) is an online information provider of public company documents in full-color, portable document format (PDF).

${ }^{9}$ Since the data cover 2 years, these values are calculated as the sum of each firm's percent of global market capitalization for the year it appears.

${ }^{10} \mathrm{~A}$ full list of the search terms is available from the authors.

${ }^{11}$ The terms include futures, swap or swaps, swaption.*, collar.*, derivat.*, call option.* or put option.*, hedg.*, cash flow hedg.*, fair value hedg.*, risk management, effective portion.* or ineffective portion.*, notional amount.*, option.*, contract.*, option.*, where "** signifies any additional characters. The index sums the number of these terms found in the annual report (regardless of the number of times) for a maximum score of 14 .

${ }^{12}$ Even careful examination of the annual reports does not always give clear evidence whether a firm uses derivatives or not, because some firms make very general statements about their risk management policy or accounting practices without specifically addressing the particular year in question. Given the systematic way of classifying firms and the fact that users appear to be misclassified about as often as nonusers, the results should at worst suffer from some noise with little effect on the results across the large sample of firms.
} 
or commodity price) and types of instruments (i.e., forwards/futures, swaps, and options) are collected. ${ }^{13}$

Summary statistics on the use of derivatives by the sample firms is presented in Table 1. Across all countries, $60.5 \%$ of the firms in the sample use at least one type of derivative. Exchange rate derivatives are the most common (45.5\%), followed by interest rate derivatives $(33.1 \%)$ and commodity price derivatives $(9.8 \%)$. Though usage rates for particular types of instruments vary considerably across countries, some clear patterns emerge. Forward contracts are the most frequently used exchange rate derivatives, whereas swaps are the instrument of choice for interest rate derivatives. For commodity price derivatives, the distribution of instrument type is more even. Firms in the U.S. are less likely to use exchange rate derivatives than non-U.S. firms, but U.S. firms are more frequent users of interest rate and commodity price derivatives.

All capital market data (i.e., the firms' stock return indices, stock market return indices, and interest rates) are from Datastream. These data are provided at a daily frequency. For each firm, we calculate stock returns in local currency. To begin, all time series are limited to the year of the firm's annual report. Accounting data originate from the Thomson Analytics database. ${ }^{14}$ Outliers are eliminated by winsorizing observations in the top and bottom 1 percentile as well as those observations where variable values exceed more than 5 standard deviations from the median. This filter eliminates some apparent data errors where magnitudes suggest data units are not properly reported (e.g., thousands instead of millions). Systematic differences across countries and industries are controlled for with country and 44 industry dummy variables. In order to avoid the crosssectional results being influenced by the effect of the economic cycle, we use 3 -year averages of variables where this impact seems most relevant (e.g., coverage, foreign income). In a separate analysis, we examine the performance of derivative users and nonusers through time.

\section{B. Risk Measures}

In order to study the possible determinants of corporate derivatives use, different categories of exposures to risk are employed. First, firms may differ with regard to their gross or prehedging exposure. ${ }^{15}$ For instance, measures of gross exposure with regard to foreign exchange rate risk include foreign sales (relative to total sales), foreign income (relative to total income), and foreign assets (relative to total assets). In addition to these individual proxies of foreign

\footnotetext{
${ }^{13}$ Dichotomous variables for the use of foreign debt and stock options are created in the same fashion, since this information is not readily available elsewhere.

${ }^{14}$ Data are commonly reported in millions of U.S. dollars. Many of the variables we examine are ratios and are therefore largely comparable across countries and years. However, we also examine a dummy variable for the year (2000 or 2001) and have undertaken robustness checks to make sure that our conclusions are not driven by which year we examine.

${ }^{15}$ To be precise, gross (or prehedging) exposure is a measure of exposure that does not incorporate the effect of financial derivatives.
} 
TABLE 1

\section{Summary Statistics of Derivatives Use of Sample Firms} Table 1 presents summary statistics of derivatives use by country. In particular, it presents the number of firms and the percentage of firms using derivatives, for general derivatives use, foreign exchange rate
derivatives, interest rate derivatives, and commodity price derivatives. Firms are required to be outside the financial and regulated utility sectors, and to have an annual report on the Global Reports database, accounting data on Thomson Analytics, and at least 36 nonmissing daily stock returns for the year of the annual report on Datastream. We create a category called "Other countries" for countries with less than 10 observations (i.e., Bahamas, Bermuda, Cayman Islands, Egypt, Indonesia, Peru, Portugal, Turkey, and Venezuela).

\begin{tabular}{|c|c|c|c|c|c|c|c|c|c|c|}
\hline \multirow[b]{2}{*}{ Country } & \multirow[b]{2}{*}{ Firms } & \multirow[b]{2}{*}{ General } & \multicolumn{4}{|c|}{$\begin{array}{c}\text { Foreign Exchange } \\
\text { Rate Derivatives }\end{array}$} & \multicolumn{4}{|c|}{$\begin{array}{c}\text { Interest Rate } \\
\text { Derivatives }\end{array}$} \\
\hline & & & General & Forward & Swap & Option & General & Forward & Swap & Option \\
\hline Argentina & 10 & 70.0 & 70.0 & 40.0 & 20.0 & 0.0 & 60.0 & 0.0 & 40.0 & 30.0 \\
\hline Australia & 301 & 66.4 & 52.2 & 48.5 & 8.6 & 17.9 & 42.2 & 3.7 & 38.9 & 15.0 \\
\hline Austria & 41 & 56.1 & 56.1 & 43.9 & 17.1 & 22.0 & 22.0 & 0.0 & 17.1 & 7.3 \\
\hline Belgium & 60 & 50.0 & 36.7 & 26.7 & 8.3 & 6.7 & 23.3 & 0.0 & 21.7 & 3.3 \\
\hline Brazil & 16 & 81.3 & 56.3 & 18.8 & 25.0 & 12.5 & 18.8 & 0.0 & 12.5 & 6.3 \\
\hline Canada & 537 & 60.3 & 46.2 & 34.3 & 8.0 & 8.2 & 27.2 & 0.4 & 24.2 & 3.2 \\
\hline Chile & 13 & 100.0 & 84.6 & 61.5 & 23.1 & 7.7 & 53.8 & 0.0 & 38.5 & 7.7 \\
\hline China & 32 & 12.5 & 6.3 & 6.3 & 3.1 & 0.0 & 3.1 & 0.0 & 3.1 & 0.0 \\
\hline Czech Republic & 23 & 26.1 & 13.0 & 13.0 & 4.3 & 4.3 & 17.4 & 0.0 & 13.0 & 0.0 \\
\hline Denmark & 80 & 87.5 & 80.0 & 72.5 & 12.5 & 18.8 & 26.3 & 1.3 & 21.3 & 6.3 \\
\hline Finland & 100 & 64.0 & 58.0 & 45.0 & 18.0 & 27.0 & 37.0 & 9.0 & 29.0 & 17.0 \\
\hline France & 159 & 66.0 & 52.8 & 37.1 & 22.6 & 25.8 & 44.7 & 1.9 & 38.4 & 15.1 \\
\hline Germany & 395 & 47.1 & 39.0 & 27.3 & 10.6 & 12.4 & 24.1 & 1.8 & 17.7 & 9.4 \\
\hline Greece & 19 & 21.1 & 21.1 & 10.5 & 5.3 & 5.3 & 10.5 & 0.0 & 10.5 & 0.0 \\
\hline Hong Kong & 319 & 23.2 & 18.5 & 13.8 & 4.4 & 1.3 & 7.2 & 0.3 & 5.6 & 1.3 \\
\hline Hungary & 15 & 40.0 & 33.3 & 33.3 & 6.7 & 13.3 & 13.3 & 0.0 & 13.3 & 0.0 \\
\hline India & 40 & 70.0 & 62.5 & 60.0 & 7.5 & 0.0 & 12.5 & 0.0 & 12.5 & 0.0 \\
\hline Ireland & 46 & 84.8 & 69.6 & 63.0 & 28.3 & 8.7 & 52.2 & 4.3 & 47.8 & 8.7 \\
\hline Israel & 48 & 72.9 & 68.8 & 43.8 & 2.1 & 22.9 & 12.5 & 0.0 & 10.4 & 4.2 \\
\hline Italy & 93 & 61.3 & 38.7 & 29.0 & 16.1 & 3.2 & 33.3 & 3.2 & 23.7 & 3.2 \\
\hline Japan & 366 & 81.1 & 75.4 & 71.0 & 33.1 & 17.8 & 60.4 & 0.5 & 59.3 & 14.2 \\
\hline Korea, Republic of & 24 & 70.8 & 54.2 & 41.7 & 20.8 & 12.5 & 25.0 & 0.0 & 25.0 & 0.0 \\
\hline Luxembourg & 11 & 63.6 & 45.5 & 45.5 & 9.1 & 18.2 & 27.3 & 0.0 & 18.2 & 9.1 \\
\hline Malaysia & 289 & 20.1 & 16.3 & 12.5 & 1.4 & 0.7 & 4.2 & 0.0 & 3.8 & 1.0 \\
\hline Mexico & 35 & 60.0 & 34.3 & 25.7 & 5.7 & 11.4 & 37.1 & 2.9 & 37.1 & 0.0 \\
\hline Netherlands & 131 & 56.5 & 48.1 & 38.9 & 18.3 & 12.2 & 33.6 & 1.5 & 27.5 & 9.2 \\
\hline New Zealand & 39 & 94.9 & 79.5 & 74.4 & 17.9 & 35.9 & 76.9 & 5.1 & 71.8 & 33.3 \\
\hline Norway & 85 & 67.1 & 56.5 & 48.2 & 17.6 & 17.6 & 29.4 & 2.4 & 24.7 & 5.9 \\
\hline Other countries & 21 & 52.4 & 42.9 & 33.3 & 19.0 & 4.8 & 9.5 & 0.0 & 9.5 & 0.0 \\
\hline
\end{tabular}

\begin{tabular}{|c|c|c|c|}
\hline \multicolumn{4}{|c|}{$\begin{array}{c}\text { Commodity Price } \\
\text { Derivatives }\end{array}$} \\
\hline General & Future & $\underline{\text { Swap }}$ & Option \\
\hline 40.0 & 0.0 & 20.0 & 30.0 \\
\hline 14.3 & 2.0 & 3.7 & 5.0 \\
\hline 7.3 & 2.4 & 4.9 & 2.4 \\
\hline 3.3 & 0.0 & 1.7 & 0.0 \\
\hline 18.8 & 0.0 & 6.3 & 0.0 \\
\hline 17.7 & 2.8 & 5.2 & 5.4 \\
\hline 15.4 & 0.0 & 7.7 & 7.7 \\
\hline 3.1 & 3.1 & 0.0 & 0.0 \\
\hline 0.0 & 0.0 & 0.0 & 0.0 \\
\hline 5.0 & 1.3 & 2.5 & 1.3 \\
\hline 8.0 & 3.0 & 1.0 & 3.0 \\
\hline 3.8 & 1.3 & 1.3 & 0.6 \\
\hline 4.8 & 1.8 & 0.5 & 0.5 \\
\hline 5.3 & 5.3 & 0.0 & 0.0 \\
\hline 0.3 & 0.0 & 0.0 & 0.0 \\
\hline 13.3 & 0.0 & 6.7 & 0.0 \\
\hline 5.0 & 2.5 & 0.0 & 0.0 \\
\hline 13.0 & 2.2 & 6.5 & 4.3 \\
\hline 2.1 & 2.1 & 0.0 & 0.0 \\
\hline 2.2 & 1.1 & 2.2 & 0.0 \\
\hline 9.6 & 3.8 & 1.6 & 1.6 \\
\hline 8.3 & 0.0 & 0.0 & 4.2 \\
\hline 9.1 & 9.1 & 0.0 & 0.0 \\
\hline 1.0 & 0.7 & 0.0 & 0.0 \\
\hline 14.3 & 8.6 & 2.9 & 2.9 \\
\hline 4.6 & 0.8 & 0.8 & 0.8 \\
\hline 17.9 & 0.0 & 10.3 & 10.3 \\
\hline 8.2 & 2.4 & 0.0 & 3.5 \\
\hline 9.5 & 0.0 & 4.8 & 9.5 \\
\hline
\end{tabular}


exchange rate exposure, we create a variable Gross-FX-Exposure that is equal to the sum of foreign sales and foreign assets (as percent of totals) multiplied by the ratio of home-country exchange rate volatility to average exchange rate volatility (of all countries in our sample). This firm-specific and continuous variable provides a sensible relative gauge of gross exchange rate exposure, since it includes measures of both the degree of foreign currency operations and the relative volatility of the domestic currency. Foreign debt may create an exposure as well, but it could also work as a hedge.

Leverage, coverage, or the quick ratio may be indicators for gross interest rate exposure. With regard to commodity price exposure, we define an exposure variable at the industry level using U.S. input-output data from the Bureau of Economic Analysis from calendar year 2000. For each industry in our sample, we sum the value of inputs from commodity-sensitive industries and express it as a percentage of total input values. ${ }^{16}$ The resulting variable, Gross-CP-Exposure, ranges from a low of $1.6 \%$ for the recreation industry to a high of $73.9 \%$ for the oil industry. Finally, firms may also have more incentive to hedge if they are close to default. We use Altman's (1968) Z-score measure as a proxy for financial distress. For any of these measures, if firms are using derivatives primarily for hedging purposes, firms should be more likely to use derivatives if they have high measures of exposures.

Next, a firm's net (or posthedging) exposure is the result of the characteristics of its assets and liabilities, and ideally also includes the effects of offbalance-sheet transactions such as derivatives. ${ }^{17}$ Our 1st measure of net exposure is operating cash flow volatility $\left(\sigma_{\mathrm{CF}}\right)$, which we define as the standard deviation of operating margins (operating cash flow divided by total sales) using 5 years of annual data. However, operating cash flow may not be a good measure of net exposure for several reasons. First, it is not measured with much precision given the limited amount of data. Second, managers may be able to systematically manipulate values for accounting variables. Finally, operating cash flow may not account for the use of all derivatives for all firms. Specifically, if exchange rate and commodity price derivative transactions do not utilize (i.e., qualify for) "hedge accounting" they will not be reflected in operating cash flow. Similarly, the effects of most interest rate derivatives will not be reflected in operating cash flow. ${ }^{18}$ However, cash flow volatility will capture other types of risk management activities (e.g., operational hedging with foreign assets), which have been identified as important hedging tools for exchange rate risk. Thus, cash flow volatility

\footnotetext{
${ }^{16}$ Specifically, we define the following industries as commodity price sensitive: oil and gas extraction, mining, utilities, wood products, paper products, petroleum and coal products, chemical products, plastics and rubber products, primary metals, air transportation, water transportation, and truck transportation.

${ }^{17}$ To be precise, net (or posthedging) exposure is a measure of exposure that incorporates the effect of financial derivatives.

${ }^{18}$ Nonetheless, most derivative users in our sample use exchange rate and commodity price derivatives. We have also conducted all of our analysis using a measure of earnings, rather than cash flow, volatility; to conserve space, we do not report the results separately. We find similar, albeit slightly weaker, results for earnings volatility. This may be because firms take on other financial risks (e.g., greater leverage) if they can hedge some financial risks.
} 
may be affected for derivative users, even if derivatives do not qualify for hedge accounting, if derivatives are a proxy for broader "corporate hedging."19

While the risk of assets and liabilities contain different components and their interactions are difficult to decompose, the assumption of efficient capital markets suggests that net exposures can be estimated empirically using a company's stock price as an aggregate measure of relevant information. Consequently, we construct different firm-specific risk measures from stock prices. In particular, for each firm we calculate the standard deviation of its stock returns $\left(\sigma_{E}\right)$. We also examine standardized firm volatility $\left(\sigma_{E}^{*}\right)$, measured as the ratio of a firm's stock return standard deviation to the standard deviation of the returns of the local market index, to avoid a potential bias from a spurious correlation between derivatives use and overall market volatility.

The sensitivity of the firm's stock returns to the local market return is estimated using the standard market model on daily returns,

$$
R_{j t}-r_{f t}=\alpha_{j}+\beta_{j}\left(R_{M t}-r_{f t}\right)+\varepsilon_{j t}
$$

where $R_{j t}$ is the stock return of firm $j$ on day $t, R_{M t}$ is the return on the local market index $M$ on day $t$, and $r_{f t}$ is the (daily) risk-free rate of interest. ${ }^{20}$ The estimation period consists of the year for which we have the annual report data. The NeweyWest (1987) procedure is used to correct for autocorrelation and heteroskedasticity. Corporate use of derivatives for hedging purposes would be consistent with lower stock return volatility and lower measures of posthedging exposures as estimated in the regression framework. Overall (net) market exposure is measured by the estimated value $\hat{\beta}_{j}$.

Table 2 reports statistics for the risk variables used in our analysis. Returns for individual stocks, pooled across all observations, and the market index are negative on average over our sample period, -8 basis points (bp) and $-4 \mathrm{bp}$ per day, respectively. Average volatility of operating cash flow, $\sigma_{\mathrm{CF}}$, is $8.25 \%$ but very positively skewed. As a result, we also examine the natural logarithm of operating cash flow volatility in our statistical analysis. Risk as measured by $\sigma_{E}$ averages 0.56 and is somewhat positively skewed. Standardizing $\sigma_{E}$ by market volatility $\left(\sigma_{E}^{*}\right)$ suggests that the average firm has substantial idiosyncratic risk, with a standard deviation of return that is more than 2.5 times the market's volatility. Estimated market betas average 0.70, indicating that the typical firm in our sample has relatively low systematic risk. This is likely due to a selection bias from requiring an annual report in English, certain accounting variables, and capital markets data. The resulting firms are typically larger, more global, and more established firms with somewhat lower systematic risk. Despite this, we do see substantial cross-sectional dispersion in the beta estimates in the sample (more than $25 \%$ of firms in our sample have estimated values for beta that are greater

\footnotetext{
${ }^{19}$ As a robustness check we have repeated all of our tests with other measures of profit volatility and find similar results to those for cash flow volatility. Specifically, we have examined net margin, ROA, and earnings yield. Selected results using these alternative accounting measures of profits are discussed in the text.

${ }^{20}$ As a proxy for the risk-free rate we use 30-day Eurocurrency rates obtained from Datastream or, when these are unavailable, the shortest-term high quality (e.g., government) rate.
} 
than 1.0). The betas in our sample are also estimated with a good deal of precision. The median $p$-value for a 2 -tailed test against a null of 0 is 0.001 , and more than $80 \%$ of betas are different from 0 at the $10 \%$ confidence level.

\section{TABLE 2}

\section{Summary Statistics on Capital Market Data and Risk Measures}

Table 2 presents the mean, standard deviation (SD), minimum, 5th, 25th, 50th (median), 75th, and 95th percentile as well as the maximum of selected variables. In particular, it shows capital markets data such as the daily returns of the sample firms and the corresponding returns of the domestic market indices. It also presents descriptive statistics of cash flow volatility $\left(\sigma_{\mathrm{CF}}\right)$, the annualized SD of local currency stock returns $\left(\sigma_{E}\right)$, and the SD of local currency stock returns standardized by the SD of the local market index $\left(\sigma_{E}^{*}\right)$. Here, $\beta$ is the coefficient of a regression of stock returns on market index returns, and $p$-value is the corresponding significance level. All variables are defined in Table 3.

\begin{tabular}{|c|c|c|c|c|c|c|c|c|c|}
\hline \multirow[b]{2}{*}{ Variable } & \multirow[b]{2}{*}{ Mean } & \multirow[b]{2}{*}{ SD } & \multirow[b]{2}{*}{ Min } & \multicolumn{5}{|c|}{ Percentiles } & \multirow[b]{2}{*}{$\operatorname{Max}$} \\
\hline & & & & 5th & 25th & Median & 75th & 95th & \\
\hline \multicolumn{10}{|c|}{ Panel A. Capital Markets Data } \\
\hline $\begin{array}{l}\text { Stock return } \\
\text { Market return }\end{array}$ & $\begin{array}{l}-0.08 \\
-0.04\end{array}$ & $\begin{array}{l}3.71 \\
1.44\end{array}$ & $\begin{array}{l}-12.52 \\
-18.24\end{array}$ & $\begin{array}{l}-6.19 \\
-2.31\end{array}$ & $\begin{array}{l}-1.50 \\
-0.79\end{array}$ & $\begin{array}{l}0.00 \\
0.00\end{array}$ & $\begin{array}{l}1.24 \\
0.73\end{array}$ & $\begin{array}{l}6.12 \\
2.23\end{array}$ & $\begin{array}{l}13.04 \\
17.03\end{array}$ \\
\hline \multicolumn{10}{|c|}{ Panel B. Risk and Value Measures } \\
\hline $\begin{array}{l}\sigma_{\mathrm{CF}}(\%) \\
\sigma_{\mathrm{CF}}(\mathrm{log}) \\
\sigma_{E} \\
\sigma_{E}^{*} \\
\beta \\
\beta \text { (p-values) } \\
q \\
q \text { (log) }\end{array}$ & $\begin{array}{l}8.25 \\
1.34 \\
0.56 \\
2.56 \\
0.70 \\
0.10 \\
2.33 \\
0.51\end{array}$ & \begin{tabular}{r|r}
12.65 \\
1.19 \\
0.23 \\
1.14 \\
0.58 \\
0.21 \\
2.67 \\
0.74
\end{tabular} & $\begin{array}{r}0.59 \\
-0.52 \\
0.18 \\
0.72 \\
-0.18 \\
0.00 \\
0.42 \\
-0.86\end{array}$ & $\begin{array}{r}0.59 \\
-0.52 \\
0.25 \\
1.10 \\
0.01 \\
0.00 \\
0.62 \\
-0.48\end{array}$ & $\begin{array}{l}1.59 \\
0.46 \\
0.37 \\
1.70 \\
0.27 \\
0.00 \\
1.00 \\
0.00\end{array}$ & $\begin{array}{l}3.36 \\
1.21 \\
0.51 \\
2.32 \\
0.57 \\
0.00 \\
1.43 \\
0.36\end{array}$ & $\begin{array}{l}7.91 \\
2.07 \\
0.71 \\
3.24 \\
1.01 \\
0.07 \\
2.48 \\
0.91\end{array}$ & $\begin{array}{r}50.83 \\
3.93 \\
1.01 \\
4.74 \\
1.89 \\
0.65 \\
7.18 \\
1.97\end{array}$ & $\begin{array}{r}52.91 \\
3.97 \\
1.16 \\
6.05 \\
2.55 \\
1.00 \\
21.22 \\
3.06\end{array}$ \\
\hline
\end{tabular}

We define a proxy for Tobin's $q(q)$ as the sum of equity market capitalization, the book value of total debt, and the book value of preferred stock divided by the book values of each of these financing sources. The average $q$ in our sample is 2.33. The primary advantage of this method is its simplicity, which allows us to create values for nearly all firms in our sample. Alternative measures, such as those used by Allayannis and Weston (2001), rely on the use of segment and industrywide investment data that are not available for many of the firms in our global sample. Table 2 also shows that $q$ is very positively skewed. This skewness is consistent with the results of many other researchers. As a consequence, similar to Allayannis and Weston, we also examine the natural logarithm of $q$ in our statistical analysis. $^{21}$

\section{Methodology}

\section{A. Propensity Score Matching}

Previous results in the literature, which we confirm in our sample, suggest that there are substantive differences, on average, in the characteristics of firms that use derivatives and those that do not. These differences generate a selection bias when estimating the effect of derivatives on a firm and should be

\footnotetext{
${ }^{21}$ In the subsequent analysis, we only tabulate results using the natural logarithms of $\sigma_{\mathrm{CF}}$ and $q$ for brevity. However, we have also conducted all of our analysis using the levels of $\sigma_{\mathrm{CF}}$ and $q$. The results using those levels are qualitatively similar and usually statistically stronger.
} 
controlled for when we estimate the effect that derivatives have on risk and market values. Ideally, one would like to estimate the "treatment" effect by observing the same firm, under identical economic conditions, with derivatives and without derivatives in place. Since this is not possible, the 1 st method we use attempts to construct a "similar" firm to the user, where to the extent possible the "similar" firm differs only in its choice not to use derivatives.

\section{TABLE 3}

\section{Variable Definitions}

Table 3 reports the variables of the study and their definitions.

Variable

Derivatives

Foreign assets

Foreign income

Foreign sales

Gross-FX-Exposure

Foreign debt

Leverage

Coverage

Quick ratio

Z-score

Gross-CP-Exposure

Industry segments

Size (log)

Sales (log)

Dividend (dummy)

Gross profit margin

Book-to-market

$\mathrm{ROA}$

Cash flow

R\&D / sales

Earnings yield

CAPEX / sales

Tangible assets

Tobin's q (log)

Multiple share class

Stock options

Stock return

Market return

Cash flow volatility $(\sigma \mathrm{CF})$

$\sigma E$

$\sigma_{E}^{*}$

$\beta$

$\beta$ (p-value)

Alpha

Sales growth

Age (log)

Derivative market rank
Definition

Dummy variables with value 1 if firm uses derivatives, and 0 otherwise.

International assets / total assets.

International operating income / operating income (3-year average).

International sales / net sales or revenues (missing set to 0)

Sum of foreign sales and foreign assets (as percent of totals) multiplied by the ratio of homecountry exchange rate volatility to average exchange rate volatility (of all countries in our sample).

Dummy variable with value 1 if any foreign debt is reported, and 0 otherwise.

Total debt / size.

Earnings before interest and taxes (EBIT) / interest expense on debt (3y).

(Cash \& equivalents + receivables (net)) / total current liabilities.

Altman's Z-score $(6.56 \times$ (working capital / total assets) $+3.26 \times$ (retained earnings / total assets $)+6.72 \times($ EBIT / total assets $)+1.05 \times($ book value of equity + preferred stock $) /$ total debt).

Defined at the industry level using U.S. input-output data from the Bureau of Economic Analysis from calendar year 2000. For each industry, we sum the value of inputs from commodity-sensitive industries, and express it as a percent of total input values.

Number of business segments (Standard Industrial Classification (SIC) codes) that make up the company's revenue (between 1 and 8).

Natural logarithm of the sum of market capitalization, total debt, and preferred stock.

Natural logarithm of total sales.

Dummy variable with value 1 if dividend yield, dividend payout, or dividend per share is positive, and 0 otherwise.

Gross income / net sales or revenues (3-year average).

Book value per share / market price-year end.

Return on assets (3-year average)

Operating income / sales.

Research and development expense / sales (missing set to 0)

Earnings per share / end-of-year share price of common stock.

Capital expenditures / net sales or revenues (missing set to 0 ).

(Total assets - intangibles) / total assets.

Size / (book value of equity + total debt + preferred stock) (natural logarithm).

Dummy variable with value 1 if currently multiple share classes exist, and 0 otherwise.

Dummy variable with value 1 if stock options are reported in the annual report, and 0 otherwise.

Daily stock return in local currency.

Daily local stock market return in local currency.

5-year standard deviation of operating cash flow / sales.

Standard deviation of local currency stock returns (annualized).

Ratio of the daily local currency stock return standard deviation and the local currency market index standard deviation.

Coefficient of the market index from a regression of local currency stock returns on returns of the local market index.

$p$-value of the coefficient of the market index from a regression of local currency stock returns on returns of the local market index.

Intercept from a regression of local currency stock returns on returns of the local market index.

4-year growth rate of sales (4y).

Natural logarithm of the age of the firm in years.

Inverse ranking of the size of the derivatives market relative to the market of the other countries in the sample. Size is calculated by summing daily turnover in the exchange rate and interest rate markets in 2001 for nonfinancial firms and standardizing by nominal GDP. We use the rank because the unranked values are extremely positively skewed by countries with exchange rate trading centers (e.g., the U.K.).

Rather than matching on several individual firm characteristics or covariates, the method we choose matches on the propensity score (the estimated likelihood 
that a firm will use derivatives). Rosenbaum and Rubin (1983) show that matching on the covariates and matching on the propensity score will both result in a distribution of the covariates in the treated and untreated groups that is the same. An advantage of propensity score matching is that it eliminates the "curse of dimensionality" when one wishes to match on several characteristics. A disadvantage of propensity score matching is that a large sample is required to obtain a meaningful match on the propensity scores (i.e., one that allows for a precise measurement of the treatment effect). (See Zhao (2004) for more discussion on this point.)

To use this method, we model the likelihood that a firm will choose to use derivatives, $H\left(W_{i}\right)$, based on a set of variables $W_{i}$. That is, we model

$$
H_{i}=\gamma^{\prime} W_{i}+u_{i}
$$

where the observed value of $H_{i}$ is 1 if the firm chooses to use derivatives, and 0 otherwise. The variables $W_{i}$ are the characteristics of the firm that are expected to influence the choice of whether a firm uses derivatives. After the propensity scores are estimated, one can choose to match a user to the single nonuser with the most similar propensity score, or to a weighted grouping of nonusers, whose weightedaverage propensity score is similar to that of the user. One can match with or without replacement and also set up boundaries or "calipers" of various magnitudes, outside of which no matches are chosen. We use various combinations of these choices to ensure that our results are robust. We also examine various choices of the variables that are presumed to influence derivative use, $W_{i}$.

\section{B. Selection Bias}

Clearly, if there are unobserved or hidden variables that affect the decision to use derivatives, a bias may remain in the estimated effect. One advantage of the propensity score matching technique is that it allows for a sensitivity analysis on this selection bias. Rosenbaum (2002) shows that it is possible to construct an upper bound on the influence that any omitted variable would have to have on the hedging choice in order to overturn the inferences drawn. We estimate this bound and provide a comparison to the effect that any hidden bias must have, relative to the influence of the observable characteristics of the firms, to overturn the original inference. Thus, while we are not able to rule out the influence of a hidden characteristic, we can provide a benchmark for how large the effect would have to be, compared to well-known firm characteristics, to change the inferences drawn from the analysis.

\section{Variable Choice}

Many firm characteristics have been hypothesized to be relevant for the relationship between derivatives use and measures of risk and value and are therefore candidates for use as control variables. In particular, derivative use has been shown to be related to industrial diversification (number of industry segments), firm size (natural logarithm of total assets or alternatively the sum of equity market capitalization, total debt, and preferred stock), and tangible assets (as a 
fraction of total assets). Firms with more growth options, as measured by research and development (R\&D) expenses (relative to total sales) and capital expenditures (CAPEX) (relative to total sales) have been shown to be more likely to use derivatives (see, e.g., Géczy et al. (1997)). As Jin and Jorion (2006) point out, firms in certain industries may be more likely to hedge if, for example, they are exposed to more readily identified, larger, or more easily hedged types of risk.

Finally, access to derivatives markets could have an important effect on a firm's ability to execute hedging strategies. Alternatively, easy access to derivatives may facilitate engaging in derivatives transactions for purposes other than hedging because the costs of entering transactions (or more generally markets) are lower and therefore less likely to require extraordinary actions on the part of managers. As a proxy for access to derivatives markets, we use a proxy for the relative size of the derivatives market in a company's home country as measured by the derivatives market rank (Bartram, Brown, and Fehle (2009)). The definitions of these variables as well as others subsequently used in the analysis are presented in Table 3.

\section{Results}

\section{A. Univariate Results}

To begin, we compare the simple averages of risk characteristics in our sample categorized by derivative use. These results are presented in Table 4. We measure the significance of differences between the 2 types of firms using nonparametric Wilcoxon tests. Table 4 reports the $p$-values of these tests together with the means, medians, and differences in means of firm characteristics for derivative users and nonusers. While the results in Table 4 only refer to general derivatives use, the tests are also conducted separately for foreign exchange rate derivatives, interest rate derivatives, and commodity price derivatives, and differences are mentioned in the text where appropriate.

Panel A of Table 4 shows that firms using derivatives are more exposed to exchange rate risk on a prehedging basis: They have significantly more foreign sales, foreign income, foreign assets, and higher Gross-FX-Exposure. This is consistent with the use of derivatives for hedging. As measured by the existence of foreign debt, the liabilities of derivative users are also significantly more exposed to exchange rate risk (though foreign debt is also used as a risk management tool by many multinational corporations). In addition, derivative users have significantly higher gross interest rate exposure, as measured by higher leverage and lower quick ratios. In contrast, users have higher coverage ratios. Firms are more likely to belong to commodity-sensitive industries if they use derivatives (we observe a higher mean Gross-CP-Exposure for firms that use derivatives compared to those that do not). Overall, the results strongly suggest that firms are more likely to use derivatives if they have higher gross (i.e., prehedging) exposure. These tests, based on firm characteristics, are robust to analyzing derivatives separately on exchange rate risk, interest rate risk, or commodity price risk.

For most firms, asset and liability risks are unlikely to be independent. Consequently, we examine more comprehensive risk measures based on the firms' 
TABLE 4

Univariate Tests of Corporate Risk Measures and Derivatives Use

Table 4 presents the number of observations $(N)$, mean, median, and difference in mean of different risk characteristics for derivative users and derivative nonusers. The last column presents $p$-values of Wilcoxon rank sum tests between derivative users and nonusers. All variables are defined in Table 3.

\begin{tabular}{|c|c|c|c|c|c|c|c|c|}
\hline \multirow[b]{2}{*}{ Variable } & \multicolumn{3}{|c|}{ User } & \multicolumn{3}{|c|}{ Nonuser } & \multirow{2}{*}{$\begin{array}{c}\text { Difference } \\
\text { in Means } \\
\end{array}$} & \multirow{2}{*}{$\begin{array}{c}\text { Wilcoxon } \\
p \text {-Value } \\
\end{array}$} \\
\hline & $N$ & Mean & Median & $N$ & Mean & Median & & \\
\hline \multicolumn{9}{|l|}{ Panel A. Gross Exposure } \\
\hline Foreign sales & 4,167 & 0.272 & 0.152 & 2,721 & 0.164 & 0.000 & 0.108 & $<0.001$ \\
\hline Foreign income & 2,421 & 0.235 & 0.056 & 1,477 & 0.143 & 0.000 & 0.092 & $<0.001$ \\
\hline Foreign assets & 2,349 & 0.182 & 0.099 & 1,205 & 0.114 & 0.000 & 0.068 & $<0.001$ \\
\hline Gross-FX-Exposure & 4,167 & 0.379 & 0.196 & 2,721 & 0.176 & 0.000 & 0.203 & $<0.001$ \\
\hline Foreign debt & 4,167 & 0.882 & 1.000 & 2,721 & 0.725 & 1.000 & 0.157 & $<0.001$ \\
\hline Leverage & 4,091 & 0.297 & 0.254 & 2,643 & 0.189 & 0.081 & 0.108 & $<0.001$ \\
\hline Quick ratio & 4,052 & 1.380 & 0.913 & 2,616 & 2.455 & 1.345 & 1.075 & $<0.001$ \\
\hline Coverage & 4,114 & 3.852 & 3.657 & 2,655 & 2.542 & 3.333 & 1.310 & $<0.001$ \\
\hline Gross-CP-Exposure & 4,167 & 0.151 & 0.106 & 2,721 & 0.114 & 0.051 & 0.100 & $<0.001$ \\
\hline \multicolumn{9}{|c|}{ Panel B. Net Risk and Value } \\
\hline$\sigma_{\mathrm{CF}}(\%)$ & 3,365 & 6.200 & 2.848 & 1,768 & 12.162 & 4.994 & -5.962 & $<0.001$ \\
\hline$\sigma_{\mathrm{CF}}(\log )$ & 3,365 & 1.144 & 1.046 & 1,768 & 1.717 & 1.608 & -0.573 & $<0.001$ \\
\hline & 4,167 & 0.510 & 0.461 & 2,721 & 0.624 & 0.604 & -0.114 & $<0.001$ \\
\hline$\sigma_{E}^{*}$ & 4,167 & 2.380 & 2.140 & 2,721 & 2.842 & 2.705 & -0.462 & $<0.001$ \\
\hline$\beta^{L}$ & 4,165 & 0.686 & 0.540 & 2,721 & 0.732 & 0.618 & -0.046 & $<0.001$ \\
\hline$q$ & 3,980 & 2.154 & 1.392 & 2,559 & 2.605 & 1.564 & -0.451 & 0.005 \\
\hline$q(\log )$ & 3,980 & 0.480 & 0.331 & 2,559 & 0.556 & 0.447 & -0.076 & 0.005 \\
\hline Alpha & 4,165 & -0.061 & 0.008 & 2,721 & -0.236 & -0.114 & 0.175 & $<0.001$ \\
\hline \multicolumn{9}{|c|}{ Panel C. Other Firm Characteristics } \\
\hline Z-score & 3,566 & 5.515 & 3.471 & 1,971 & 8.888 & 5.688 & -3.373 & $<0.001$ \\
\hline Size (log) & 4,126 & 6.580 & 6.555 & 2,680 & 4.783 & 4.731 & 1.797 & $<0.001$ \\
\hline Sales $(\log )$ & 4,091 & 6.713 & 6.691 & 2,643 & 5.063 & 4.941 & 1.650 & $<0.001$ \\
\hline Industry segments & 4,150 & 3.823 & 3.000 & 2,710 & 3.420 & 3.000 & 0.403 & $<0.001$ \\
\hline Dividend (dummy) & 4,167 & 0.598 & 1.000 & 2,721 & 0.400 & 0.000 & 0.198 & $<0.001$ \\
\hline R\&D / size & 4,167 & 0.044 & 0.000 & 2,721 & 0.121 & 0.000 & -0.077 & $<0.001$ \\
\hline CAPEX / size & 4,172 & 0.126 & 0.050 & 2,724 & 0.174 & 0.047 & -0.048 & 0.011 \\
\hline Tangible assets & 3,882 & 0.874 & 0.943 & 2,554 & 0.888 & 0.973 & -0.014 & $<0.001$ \\
\hline Stock options & 4,172 & 0.828 & 1.000 & 2,724 & 0.792 & 1.000 & 0.036 & $<0.001$ \\
\hline Sales growth & 3,452 & 10.513 & 6.450 & 1,821 & 13.774 & 8.861 & -3.261 & $<0.001$ \\
\hline Derivative market rank & 4,167 & 38.299 & 43.000 & 2,721 & 36.083 & 41.000 & 2.216 & $<0.001$ \\
\hline
\end{tabular}

cash flow measures and stock returns. Studying stock prices is informative, since they represent an aggregate measure of asset and liability risk and should also incorporate the effects of financial risk management. If derivatives are used for hedging purposes, firms with high prehedging exposure should be more likely to use them and, consequently, might exhibit similar, or even lower, posthedging (net) exposure.

Despite the higher exposures documented in Panel A of Table 4, the univariate results in Panel B of Table 4 shows that derivative users have significantly lower cash flow volatility, total risk, and market risk. In particular, the average $\sigma_{\mathrm{CF}}(\log )$ is more than $30 \%$ lower for users, and $\sigma_{E}$ and $\sigma_{E}^{*}$ are about $20 \%$ lower for derivative users. Likewise, market betas are on average about $6 \%$ lower for derivative users. These results provide some support for the hypothesis that, on average, firms are hedging rather than speculating with derivatives. At a univariate level, the unadjusted Tobin's $q$ of the average derivative user is $17 \%$ lower than for the average firm that does not use derivatives. However, we also see that the unconditional relative performance of users as measured by the market-model alpha is significantly higher in our sample period. 
Panel $\mathrm{C}$ of Table 4 shows that there are further significant differences in the characteristics of firms that use derivatives and those that do not. For example, derivative users have lower $Z$-scores, are significantly larger, and are more diversified. They are also more likely to pay dividends and to have executive stock options. However, derivative users also tend to have fewer tangible assets, lower R\&D expenses, and lower CAPEX. As expected, firms are more likely to use derivatives if the market for derivatives (among dealers) is more developed.

We repeat the analysis for the firm-specific variables in Table 4 after each variable has been adjusted for country and industry fixed effects (results are not tabulated). The results are largely unaffected, although in some instances statistical significance is reduced. The most striking difference in this respect is that users no longer have a significantly lower $q$ after taking country and industry effects into account. The results for risk measures are quite similar to those presented in Table 4. Overall, the univariate results suggest that nonfinancial firms use derivatives in line with hedging motives. These findings also clearly show large differences in the characteristics of derivative users and nonusers that should be controlled for. In the next section, we undertake a multivariate analysis for this purpose.

\section{B. Multivariate Results}

\section{Propensity Score Matching: Risk Measures}

We begin with a matching analysis. Specifically, we match derivative users with nonusers on the basis of their propensity score, which is a measure of the firms' propensity to use derivatives based on the firms' unique characteristics. Several choices must be made in order to use propensity score matching. As in any matching analysis, in making these choices we are trading off the precision of the matching criteria against the sample size. We explore a number of different specifications and present several representative specifications. In general, our results are robust across most specifications; we note differences in results where they occur.

In conducting the propensity score matching the first choice is the selection of independent variables that are hypothesized to influence firms' likelihood of using derivatives. We use variables that have been shown elsewhere to be associated with derivative use and risk exposure, as well as variables that incorporate the broader nature of our sample. Specifically, we include Altman's (1968) Z-score, firm size, leverage, a liquidity variable (quick ratio), and a market access variable (a dummy variable for multiple share classes). In some specifications we also include a variable related to managerial incentives to hedge (stock option use), Gross-FX-Exposure, a dummy variable for existence of foreign currency debt, as well as country and industry dummy variables (where noted). For $q$, we also include variables shown by other studies to be associated with firm value such as dividend payout, sales growth, R\&D expenditures, and CAPEX.

The most important determinants of derivatives use are not surprising. Consistent with the univariate results, firm size, leverage, the multiple share class dummy variable, the stock options dummy variable, exchange rate exposure, and the foreign debt dummy variable are positively related to the probability 
of derivative use, whereas the $Z$-score and quick ratio exhibit negative relations. In addition, many, but not all, industry and country dummy variables are statistically different from each other. Furthermore, matching on these factors is important for our analysis, since other studies have shown some to be related to risk and value measures. For example, Bartram, Brown, and Stulz (2011) find that firm size, leverage, and liquidity are important determinants of both total risk and systematic risk. Allayannis and Weston (2001) find that size, growth, leverage, and dividends are related to firm value. The relations we observe are intuitive (results are not tabulated). Larger firms are likely to have more stable sales and thus lower cash flow and equity price risk. Conversely, firms with more financial leverage or that have a higher chance of financial distress should have higher risk. Firm value is increasing in firm profitability and growth, since these lead to higher cash flows to equity holders, but is decreasing with age and size, since these firms are likely to be more established and thus less likely to have large new profit opportunities.

The second choice in the matching analysis is the construction of the matching nonuser. The analysis can simply choose a single, "nearest neighbor" match, or use a weighted average of many (or all) nonusers to construct a match. One can sample from the nonusers with or without replacement. One can set conditions outside of which no matches will be found (i.e., caliper matching). We conduct our analysis using 2 different matching criteria (with and without replacement), and 3 different choices of matching parameters, for 6 specifications in all.

In assessing the propensity score method's success, it is important to know the extent to which the propensity score matching succeeds in removing the selection bias in the observed characteristics of firms in the 2 subsamples. Consequently, for each characteristic, we calculate the bias measure

$$
\mathrm{BIAS}=\left|\frac{100\left(\mu_{T}-\mu_{C}\right)}{\sqrt{\left(s_{T}^{2}+s_{C}^{2}\right) / 2}}\right|,
$$

where $\mu_{T}$ and $s_{T}$ are the sample mean and standard deviation of the characteristic for the user, and $\mu_{C}$ and $s_{C}$ are the sample mean and standard deviation for the characteristic in the matching control firms, respectively. In general, the matching methods substantially reduce the difference in characteristics across test and matched firms (although to save space, we do not tabulate the results). Without propensity score matching, we find that the bias in the characteristics in the raw data is quite large; for example, the bias in market capitalization is greater than $90 \%$, while the biases in leverage, foreign exposure, and foreign debt are all greater than $40 \%$. The specifications that allow for replacement of the nontreated firms in the sample reduce the bias so that none of the characteristics is associated with a bias of more than $16 \%$, and most are below $10 \% .^{22}$ Overall, the matching procedure does a good job of producing "balanced covariates" across the 2 subsamples.

\footnotetext{
${ }^{22}$ While both of the matching specifications we consider reduce the bias considerably, the specification that does not allow for replacement still contains substantial biases with respect to market capitalization, foreign debt, and foreign exchange rate exposure.
} 
In the subsequent analysis, we examine results from all 6 methods but only report results using matching with replacement to save space. We discuss differences when appropriate. We prefer the results with replacement because this leads to greater reductions in selection bias (as noted previously), maximizes the sample size of derivative users, and eliminates the need to determine which derivative users to include in the analysis. Regardless, our conclusions are not sensitive to whether we examine results of tests with or without replacement.

Table 5 presents the results of representative propensity score estimation for each of the 4 primary variables we examine $\left(\sigma_{\mathrm{CF}}, \sigma_{E}, \beta\right.$, and $\left.q\right)$. For each of these 4 variables, we report the number of firms, mean, and median values of the characteristic for the firms that use derivatives and those that do not, and provide a measure of the difference in means as well as a statistical test of the significance of the difference between the 2 subsamples of firms.

\section{TABLE 5}

\section{Matched-Sample Tests of Corporate Risk Measures and Derivatives Use}

\begin{tabular}{|c|c|c|c|c|c|c|c|c|}
\hline \multirow[b]{2}{*}{$\begin{array}{l}\text { Variable: } \\
\text { Specification } \\
\end{array}$} & \multirow[b]{2}{*}{$\begin{array}{c}\text { Country and } \\
\text { Industry Dummies }\end{array}$} & \multirow[b]{2}{*}{$N$} & \multicolumn{2}{|c|}{ Users } & \multicolumn{2}{|c|}{ Nonusers } & \multirow[b]{2}{*}{$\begin{array}{l}\text { Diff. in } \\
\text { Means } \\
\end{array}$} & \multirow[b]{2}{*}{$\begin{array}{c}\text { Wilcoxon } \\
p \text {-Value } \\
\end{array}$} \\
\hline & & & Mean & Median & Mean & Median & & \\
\hline \multicolumn{9}{|l|}{$\overline{\sigma_{\mathrm{CF}}(\log ):}$} \\
\hline 1 & Yes & 2,440 & 0.997 & 0.907 & 1.074 & 0.945 & -0.077 & $<0.001$ \\
\hline 2 & Yes & 2,440 & 0.996 & 0.907 & 1.152 & 1.019 & -0.156 & $<0.001$ \\
\hline 3 & No & 2,510 & 1.000 & 0.913 & 1.215 & 1.110 & -0.215 & $<0.001$ \\
\hline \multicolumn{9}{|l|}{$\sigma_{E}:$} \\
\hline 1 & Yes & 3,490 & 0.500 & 0.456 & 0.524 & 0.495 & -0.024 & $<0.001$ \\
\hline 2 & Yes & 3,490 & 0.500 & 0.456 & 0.546 & 0.512 & -0.046 & $<0.001$ \\
\hline 3 & No & 3,507 & 0.498 & 0.454 & 0.551 & 0.519 & -0.053 & $<0.001$ \\
\hline \multicolumn{9}{|l|}{$\beta:$} \\
\hline 1 & Yes & 3,490 & 0.663 & 0.528 & 0.745 & 0.653 & -0.138 & $<0.001$ \\
\hline 2 & Yes & 3,490 & 0.663 & 0.528 & 0.757 & 0.700 & -0.113 & $<0.001$ \\
\hline 3 & No & 3,507 & 0.661 & 0.528 & 0.806 & 0.712 & -0.249 & $<0.001$ \\
\hline \multicolumn{9}{|l|}{ q: } \\
\hline 1 & Yes & 2,076 & 0.451 & 0.312 & 0.385 & 0.255 & 0.066 & 0.015 \\
\hline 2 & Yes & 1,956 & 0.453 & 0.323 & 0.401 & 0.291 & 0.052 & 0.089 \\
\hline 3 & No & 2,137 & 0.454 & 0.315 & 0.329 & 0.238 & 0.125 & $<0.001$ \\
\hline
\end{tabular}

Regardless of the parameters chosen for the construction of the matching nonderivative users, we find significantly lower values for cash flow volatility $\left(\sigma_{\mathrm{CF}}\right)$, standard deviation of returns $\left(\sigma_{E}\right)$, and beta risk $(\beta)$ for firms that use derivatives. Across the various specifications, the differentials in $\sigma_{\mathrm{CF}}$ range from approximately $8 \%$ to $20 \%$; for $\sigma_{E}$ the reduction varies from between $5 \%$ to $10 \%$; the differential in $\beta$ varies from between $15 \%$ and $31 \%$. Calculating the differentials using medians gives a similar result, as do all the other specifications we 
consider. Differences of this magnitude should have a material effect on a firm's cost of capital. For example, consider the capital asset pricing model (CAPM) with a 5\% market risk premium; a decline in $\beta$ of 0.15 results in a $75-b p$ reduction in the cost of equity.

Regardless of the specification, we find that the average values of $q$ for firms that use derivatives are higher than for those that do not; however, the result is statistically weaker than the risk results, with $p$-values across specifications ranging between $<0.001$ and 0.100 . The magnitude of the estimated effect also varies across different specifications, but is always economically large, ranging from about $7 \%$ to $14 \%$ (in levels).

The results in Table 5 suggest that, after controlling for other firm characteristics, derivative contract use is associated with statistically and economically significantly lower cash flow and stock return volatility, as well as with lower systematic risk. The statistical evidence for an increase in value is weaker; however, the economic magnitude of the estimated change in value is always nontrivial.

\section{What about the Selection Bias?}

Although the propensity score matching represents one way to correct for selection bias, it assumes that all of the differences between firms that drive the difference in derivative use are observable; Rosenbaum and Rubin (1983) call this assumption "unconfoundedness." More specifically, they assume that observations with the same propensity score have the same distribution of unobservable characteristics, independent of their treatment status. If this assumption does not hold then there will be a hidden bias in the results. That is, if there are unobserved variables that affect whether a firm decides to use derivatives, as well as the risk and value outcomes, then our inferences may be incorrect.

Since the problem variables are, by definition, unobserved, we cannot estimate their effect directly. However, using the propensity score matching technique, Rosenbaum (2002) calculates a bound on how large an effect the unobserved variables would have to have on the selection process in order to change the inferences provided by the propensity score matching analysis. Intuitively, this bound is based on the calculation of an odds ratio. If 2 firms have identical observable characteristics, the expected value of the odds ratio that they will choose to use derivatives is 1 in the absence of a hidden bias. However, if there is a hidden bias in the estimation, and the firms differ in the unobserved characteristic, then the chance that the firms will differ in their choice of derivatives varies more widely, and the precision of the inferences declines. The calculation of the bounds is essentially a sensitivity analysis; first, one sets the size of the hidden bias, and thus the size of its effect on the odds ratio, to a particular level. Next, following Rosenbaum, one recalculates a new (larger) confidence interval for the $p$-value on the difference of each of the relevant characteristics based on this level of hidden bias. The level of hidden bias is then incremented, and the recalculation is repeated. ${ }^{23}$ As DiPrete and Gangl (2004) point out, the Rosenbaum bound is

\footnotetext{
${ }^{23}$ We calculate these bounds individually for each characteristic. Although one could in theory calculate a joint bound for a combination of variables, this requires that one assumes, or separately
} 
a "worst-case" scenario: It tells the observer not that the treatment effect is not present, but at what point the confidence interval would include 0 "if this [unobserved] variable's effect ... . was so strong as to almost perfectly determine [the effect of derivative use] for each pair of matched cases in the data." In that respect, the results of the Rosenbaum bound analysis are conservative.

In Table 6, we calculate the Rosenbaum (2002) bounds for the matching specifications presented in Table 5, where the variables of interest are $\sigma_{\mathrm{CF}}, \sigma_{E}, \beta$, and $q$. The gamma variable indicates the generated, or preset, size of the hidden bias for each specification, which is required for the critical $p$-value associated with that inference to be larger than 0.05 . For example, a gamma of 1.5 indicates that the unobserved variable is associated with a 50\% change in the odds ratio of whether a firm uses derivatives. In row 1 of Panel A, the bias level (gamma value) of 1.18 is associated with the critical probability of 5\%; thus, to overturn the inference on cash flow volatility in the data, or, equivalently, to become less than $95 \%$ confident that derivative use is associated with a decline in cash flow volatility, users would have to be $18 \%$ more likely to possess some hidden trait than nonusers. Clearly, higher values of gamma suggest a less important potential hidden bias problem.

Once the bound is calculated, the interpretation of how severe the hidden bias problem is, or the economic interpretation of the level of gamma required to overturn inferences, is subjective. However, following DiPrete and Gangl (2004), we can compare the change in inferences, which is potentially caused by unobserved variables, given by the Rosenbaum (2002) bounds, to the equivalent effect of observed variables, since we have estimates of the effect of the observables on the decision to use derivatives. These values are given in the remaining (numeric) columns of Table 6.

For example, in the first specification for $\sigma_{E}$, we see that for an unobserved variable to cause a hidden bias that affects our inferences on standard deviation of total return, that variable would have to have an effect equivalent to at least a difference of 0.40 in leverage. This difference is approximately twice the average leverage level of nonusers in the sample, or approximately 1.5 times the standard deviation of leverage for nonusers. Similarly, a missing variable would have to be equivalent to the effect of a difference in log size of 1.07. This represents a dollar difference of about $\$ 2$ billion, or several times the average market value of nonusers in our sample.

The general interpretation for the inferences on the effect of derivative use on total risk and systematic risk is similar: To overturn the inference that derivative use reduces risk, an unobserved confounding variable must have an impact that is comparable in magnitude to economically large changes in firm characteristics, such as leverage, market capitalization, or risk exposure. Moreover, such an unobserved variable would have to be unrelated to the other control variables we use. The inferences for the effect of derivative use on cash flow risk appear to be

estimates, the relation between the combination of characteristics of interest (see DiPrete and Gangl (2004) for an example of such a specification). Given the large number of characteristics we consider, and the difficulty in estimating their interrelationships, we do not perform such an analysis. Consequently, the bounds we report should be interpreted with some caution. It is certainly possible that smaller changes in multiple variables would be sufficient to overturn inferences. 


\section{TABLE 6}

\section{Rosenbaum Bounds for Matching}

Table 6 presents the Rosenbaum (2002) bounds and hidden bias equivalents for different outcome variables. Each set of results shows columns for gamma (the change in the odds ratio), for a critical p-value of 0.05 as well as hidden bias equivalents for various firm characteristics for each of the 3 specifications reported in Table 5 . Users and nonusers are matched by propensity scores sampling without replacement. Panel A shows results for cash flow volatility $\left(\sigma_{\mathrm{CF}}\right)$, stock return volatility $\left(\sigma_{E}\right)$, and market betas $(\beta)$. Panel $\mathrm{D}$ reports results for Tobin's $q$ (log). Propensity scores are based on the set of variables in the column headings as well as industry and country dummy variables. All variables are defined in Table 3 .

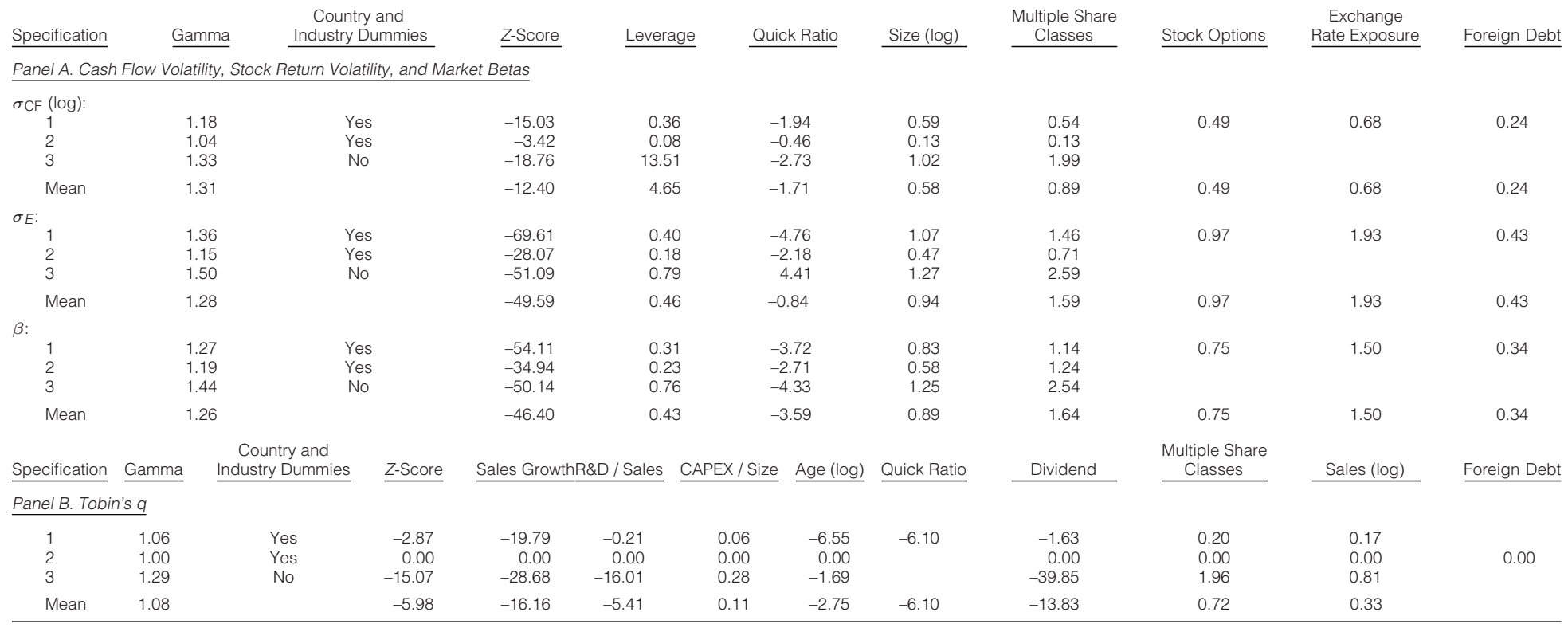


slightly more sensitive to selection bias. For example, in specification 2 if users are only about $5 \%$ more likely to possess some hidden characteristic that is associated with derivative use, the inferences could be overturned. In the remaining specifications, the magnitude of the hidden bias is large and roughly comparable to those estimated for total risk. The average gammas and sensitivities are comparable to those for total risk and systematic risk. ${ }^{24}$

Finally, the results with respect to the value premium appear to be even more sensitive to hidden bias, using most of the propensity score matching techniques. For example, specification 2 shows that inferences are potentially overturned at any level of bias. ${ }^{25}$ Consequently, the effect of derivative use on market value is highly affected by even a small degree of selection bias in the sample. The sensitivity of the value differential associated with derivative use to selection bias may explain the mixed results in the literature. This result suggests that the estimated value premium (or discount) may be heavily dependent on the sample, the control variables used, and the specification method employed in the tests. At a minimum, these results suggest that the inference that hedging increases firm value should be treated very cautiously.

\section{Robustness Checks}

We conduct a series of robustness checks on our results. As a robustness check on the matching results, we use the same binary variable to measure derivative use, and estimate a treatment effects model as in Heckman (1979). We find similar results: Derivative use is associated with significantly lower measures of risk. Likewise, the relation of derivative use to Tobin's $q$ is significantly positive. We also use a measure of derivative use intensity, rather than merely derivative use, as the variable of interest, as well as an instrumental variables technique to measure the effect of derivative use on the firm. ${ }^{26}$ The results are similar in sign, but weaker in statistical significance. The use of a broader array of derivative contracts is associated with lower cash flow volatility; the results for idiosyncratic volatility and systematic risk are negative, but not statistically significant, while the relation between additional contract use and relative market value is positive but not statistically significant. This indicates that the documented differences in risk and value are more strongly associated with any use of derivatives rather than the extent of use of derivatives. In turn, this may suggest that derivative use serves as a proxy for broader financial risk management policies. ${ }^{27}$

\footnotetext{
${ }^{24}$ In some cases, the change in the independent variable that would be required to overturn the bounds is not physically possible. For example, consider the change in the $Z$-score column where large negative changes (e.g., 15.03, observed in row 1) would not be observable. This suggests that the inferences about the effect of derivative use on risk could not be overturned by any possible change in this measure of financial distress. Of course, this does not imply that another, omitted variable may not be important, but this variable must be unrelated to the $Z$-score.

${ }^{25}$ Note that the $p$-value is above the critical value at a gamma level of 1.0. Recall that in this specification of the propensity score matching, the difference in Tobin's $q$ across users and nonusers is not significant (see Table 5).

${ }^{26}$ From these binary variables, we create a variable equal to the sum of the categories for which we document firms using derivatives. For example, a firm that uses exchange rate forwards, exchange rate options, and interest rate swaps would have a hedging intensity of 3 .

${ }^{27}$ Related to this test, we examined differences in the risk measures of firms that use only interest rate derivatives and firms that used interest rate derivatives along with some other contract(s). Since
} 
Finally, we estimate a series of simultaneous equations models, similar to the specification employed in Graham and Rogers (2002), in which derivatives use and 3 alternate measures of risk (volatility of cash flow, standard deviation, and normalized standard deviation of returns) are dependent variables in a system of 2 equations that include other control variables. In untabulated results (available from the authors), we continue to find that derivative use is associated with a decline in the volatility of all 3 measures of risk, with $p$-values on the coefficient associated with derivative use ranging from 0.03 to 0.06 .

These models also have the advantage that we can estimate the effects of other variables on firm risk and value after accounting for the use of derivatives. We find that line-of-business diversification, dividend payout, and profitability tend to be negatively related to $\sigma_{\mathrm{CF}}, \sigma_{E}$, and $\beta$; leverage is positively related to $\sigma_{E}$ and negatively related to $\sigma_{\mathrm{CF}}$ and $\beta$, whereas Gross-FX-Exposure is usually positively related to all 3 measures. Interestingly, firm size is positively related to $\sigma_{\mathrm{CF}}$ and $\beta$, but not a significant determinant of $\sigma_{E}$. For $q$ we find that firm size, dividend payout, $R \& D$ expenditures, and leverage have negative coefficients, and profitability has a positive coefficient. We find no evidence of a diversification discount (i.e., the coefficient on the number of industry segments variable is not statistically significant). The result for R\&D expenditures is somewhat surprising but may be the result of the sample period when tech companies with high R\&D spending had low market returns.

Overall, the results from using alternative measures of derivative use, as well as different methods, are consistent with those presented previously: The use of derivatives by firms is associated with a significant decline in risk, while effects on value tend to be positive but statistically weaker.

\section{Time-Series Evidence}

As noted already, our sample period encompasses a period of economic decline and a sharp market correction. During 2001, the majority of countries in our sample experienced a significant economic downturn with many experiencing a recession. For example, the United States experienced a recession from March 2001 through November 2001 and a so-called "jobless recovery" for more than the next 12 months. Global equity markets also declined sharply in this period, with the U.S. markets experiencing decline in each year from 2000 to 2002. The economic and financial dislocation led to an uptick in corporate bankruptcies as well as a drastic decline in new and seasoned equity issuances. ${ }^{28}$ Consequently, if one goal of financial risk management with derivatives is to lower the probability

interest rate derivatives by themselves should not affect operating cash flows (only net income), any differences in the volatility of operating cash flow should be attributable to the direct effects of (other) hedging on risk. In matching tests, however, there is no significant difference between firms that use only interest derivatives and those that use more extensive derivative contracts. This is consistent with (any) derivative use serving as a proxy for a host of risk management strategies employed by the firm, rather than specific derivative contracts each having a discretely measurable effect on different risks borne by the firm.

${ }^{28}$ For example, data provided by Jay Ritter (http://bear.cba.ufl.edu/ritter/publ_papers/IPOALL.xls) show that the number of initial public offerings in the United States declined from 505 in 1999 to only 84 in 2001. 
of financial distress, then firms that manage risk may have experienced significant benefits during this period.

We examine this hypothesis by calculating the time series of annual differences in adjusted risk measures (1998-2003) for firms in our sample that use, and do not use, derivatives. We compute these differences only across the subsamples of firms for which sufficient data are available. Since several additional years of data are necessary to calculate cash flow volatility, we omit this variable from our analysis. We assume that derivative use is constant over this time period and so classify firms as users or nonusers over the entire period. ${ }^{29}$

Table 7 reports the results of this analysis using the matched sample method presented in Table 5; for brevity, we report results for only 1 matching specification (specification 1 in previous tables). In Panel A, we present the time series of 2 risk measures, $\sigma_{E}$ and $\beta$. Results for $\sigma_{E}$ show that derivative users have lower total risk in each year (at better than the 0.001 significance level). The difference in 2000 is the largest but does not stand out. Results for $\beta$ also show consistently lower levels of risk for derivative users. The results are fairly stable across years, with the differences for 2000 and 2001 only slightly higher than the average of all years. The economic significance of these results is similar to that observed in Table 5.

Although we observe consistently lower levels of risk for derivative users throughout our sample period, lower risk may add more value in times of financial or economic declines. To examine this possibility, Panel B of Table 7 presents 2 measures of value: annual differences in Tobin's $q$, and measures of alpha $\left(\alpha_{j}\right)$ from our estimates of equation (1).

Measured by Tobin's $q$, the only year with a statistically significant premium (at the 10\% confidence level) is 2001 (a year that witnessed both the slowest global gross domestic product (GDP) growth in over a decade and a recession in the United States). When we examine differences in matched alphas each year, users experience significantly higher alphas than nonusers in each year except 1998. The positive difference in 2000 is the largest in the sample period and is economically quite large $(5.9 \%)$ compared to the average difference across all years $(2 \%)$.

Panel C of Table 7 presents the time series of various measures of profitability, including ROA, cash flow, and earnings yield. For each measure, profits are significantly higher (at the $10 \%$ confidence level) for derivative users in 2000 through 2002. Just as importantly, the better profitability of derivative users is due to more stable profits over this 6-year period, with nonusers exhibiting much sharper declines from 2000 to 2001 than derivative users. For example, ROA declines for derivative users from 0.064 in 2000 to 0.033 in 2001, a drop of about $50 \%$, while it declines by approximately $75 \%$ for nonusers. Cash flow declines by 0.015 from 2000 to 2001 for firms that use derivatives (or approximately $14 \%$ ) and by 0.028 (or about $30 \%$ ) for nonusers in the same period. Earnings yield for nonusers shows evidence of a decline earlier than derivative users: Earnings in

\footnotetext{
${ }^{29}$ To evaluate the validity of this assumption, we examined the use of a random sample of 50 users and 50 nonusers in 1998 and 2003. Of the firms with available data, $84 \%$ of the nonusers and $82 \%$ of the users followed the same strategy in 1998 and 2003 as in 2000-2001.
} 
TABLE 7

Matched-Sample Tests of Corporate Risk Measures and Derivatives Use across Time

Table 7 presents the mean value of risk measures (Panel A), value measures (Panel B), and profit measures (Panel C) by year for derivative users and nonusers based on propensity score matched samples. The $p$-values are from Wilcoxon rank sum tests between derivative users and nonusers. Results are shown for matching by year with replacement using the matching options "caliper (0.01) trim(1) common." The following variables are used as explanatory variables of derivatives usage. For stock return volatility, market betas, and profit measures: Z-score, leverage, quick ratio, size (log), multiple share classes, stock options, gross exchange rate exposure, foreign debt, and industry and country dummy variables; for Tobin's q and Alpha: Z-score, sales growth, R\&D / size, CAPEX / size, age (log), quick ratio, sales (log), dividend (dummy), multiple share classes, stock options, gross exchange rate exposure, foreign debt, and industry and country dummy variables. All variables are defined in Table 3.

\begin{tabular}{|c|c|c|c|c|c|c|}
\hline Variable & 1998 & 1999 & 2000 & 2001 & 2002 & 2003 \\
\hline \multicolumn{7}{|c|}{ Panel A. Risk Measures } \\
\hline \multicolumn{7}{|l|}{$\sigma_{E}:$} \\
\hline User & 0.430 & 0.422 & 0.483 & 0.460 & 0.443 & 0.372 \\
\hline Nonuser & 0.455 & 0.456 & 0.525 & 0.479 & 0.467 & 0.411 \\
\hline Difference & -0.025 & -0.034 & -0.042 & -0.019 & -0.024 & -0.039 \\
\hline$p$-value & $<0.001$ & $<0.001$ & $<0.001$ & $<0.001$ & $<0.001$ & $<0.001$ \\
\hline \multicolumn{7}{|l|}{$\beta:$} \\
\hline User & 0.698 & 0.505 & 0.576 & 0.694 & 0.702 & 0.736 \\
\hline Nonuser & 0.792 & 0.580 & 0.686 & 0.814 & 0.806 & 0.847 \\
\hline Difference & -0.094 & -0.075 & -0.110 & -0.120 & -0.104 & -0.111 \\
\hline$p$-value & $<0.001$ & $<0.001$ & $<0.001$ & $<0.001$ & $<0.001$ & $<0.001$ \\
\hline \multicolumn{7}{|c|}{$\underline{\text { Panel B. Value Measures }}$} \\
\hline \multicolumn{7}{|l|}{ q: } \\
\hline User & 0.567 & 0.564 & 0.507 & 0.435 & 0.287 & 0.434 \\
\hline Nonuser & 0.558 & 0.577 & 0.593 & 0.392 & 0.267 & 0.471 \\
\hline Difference & 0.009 & -0.013 & -0.086 & 0.043 & 0.020 & -0.037 \\
\hline$p$-value & 0.560 & 0.071 & 0.001 & 0.071 & 0.152 & 0.001 \\
\hline \multicolumn{7}{|c|}{ Alpha (annualized): } \\
\hline User & -0.149 & -0.010 & -0.029 & -0.003 & -0.061 & 0.142 \\
\hline Nonuser & -0.088 & -0.045 & -0.088 & -0.018 & -0.102 & 0.110 \\
\hline Difference & -0.061 & 0.035 & 0.059 & 0.015 & 0.041 & 0.032 \\
\hline$p$-value & $<0.001$ & 0.004 & $<0.001$ & 0.047 & $<0.001$ & 0.007 \\
\hline \multicolumn{7}{|c|}{ Panel C. Profit Measures } \\
\hline \multicolumn{7}{|c|}{ Return on Assets (ROA): } \\
\hline User & 0.063 & 0.066 & 0.064 & 0.033 & 0.015 & 0.031 \\
\hline Nonuser & 0.055 & 0.062 & 0.060 & 0.015 & -0.006 & 0.029 \\
\hline Difference & 0.008 & 0.004 & 0.004 & 0.018 & 0.021 & 0.002 \\
\hline$p$-value & 0.045 & 0.364 & 0.070 & $<0.001$ & $<0.001$ & 0.548 \\
\hline \multicolumn{7}{|l|}{ Cash Flow: } \\
\hline User & 0.108 & 0.112 & 0.108 & 0.093 & 0.091 & 0.099 \\
\hline Nonuser & 0.087 & 0.105 & 0.093 & 0.065 & 0.050 & 0.073 \\
\hline Difference & 0.021 & 0.007 & 0.015 & 0.028 & 0.041 & 0.026 \\
\hline$p$-value & $<0.001$ & 0.415 & $<0.001$ & $<0.001$ & $<0.001$ & $<0.001$ \\
\hline \multicolumn{7}{|l|}{ Earnings Yield: } \\
\hline User & 0.026 & 0.037 & 0.031 & -0.016 & -0.036 & -0.006 \\
\hline Nonuser & 0.005 & 0.028 & -0.002 & -0.049 & -0.080 & -0.003 \\
\hline Difference & 0.021 & 0.009 & 0.033 & 0.033 & 0.044 & -0.003 \\
\hline$p$-value & $<0.001$ & 0.012 & $<0.001$ & $<0.001$ & $<0.001$ & 0.184 \\
\hline
\end{tabular}

2000 for firms that do not use derivatives are essentially 0 . And, the decline in earnings from 1999 through 2001 for derivative users, at $-5.3 \%$, is smaller than for nonusers, at $-7.7 \%$.

Taken as a whole, these results suggest important time variation in a firm's risk and value measures related to financial or economic conditions. In particular, it appears that derivative use is more valuable during market downturns. To examine this possibility further, we condition our analysis on broad market returns in a firm's home country. Specifically, we create 2 equal-weighted portfolios that 
are long firms that use derivatives and short matching nonusers: The 1st portfolio includes companies in countries only when the domestic stock market index is up for the quarter; likewise, the 2 nd portfolio includes companies in countries only when the domestic stock market index is down for the quarter. We then examine the risk and return by estimating equation (1) for the years 2000-2002 and calculate the differences in market beta and alpha of each portfolio. We hypothesize that if hedging provides for lower risk in declining markets then the estimated beta will be significantly lower for the down-market portfolio as compared to the up-market portfolio. Similarly, a difference in value would be reflected in significantly higher alphas for the down-market portfolio.

Table 8 reports the results of this analysis. The table shows that the beta of the long-short portfolio is significantly negative in down markets. This simply restates the previous finding that derivative users have lower betas than nonusers. In addition, the difference in betas between the down-market and up-market portfolios is negative, which is consistent with the prediction that hedging provides downside risk protection: Nonusers are significantly more sensitive to the market portfolio, compared to firms that use derivatives, during periods of poor market returns. In fact, the statistically insignificant estimate for the beta of the up-market portfolio suggests that derivative use only provides for reliably lower risk in down markets, precisely when one would wish for lower market exposure. The difference in $\beta$ between down and up markets of -0.044 is equivalent to about a $6 \%$ difference for the average firm in our sample. The estimates of alpha are similar but not statistically significant for the difference, though the larger value for down markets is consistent with the hypothesis that hedging adds more value in down markets. In addition, the magnitude of the down-market alpha is large compared to the annual values presented in Panel B of Table 7.

\section{TABLE 8}

\section{Characteristics of a Portfolio's Long Users and Short Nonusers}

Table 8 reports characteristics of stock portfolios with equal-weighted positive investments in firms that use derivatives and short positions in matched firms that do not use derivatives. Two portfolios are generated. The 1st portfolio includes only firms in countries where the local stock market index experiences a positive quarterly return (Domestic Stock Market Up), and the 2nd portfolio includes only firms in countries where the local stock market index experiences a negative quarterly return (Domestic Stock Market Down). Values are reported for market beta and alpha. Values are estimated for the 2000-2002 period, which includes 687 down-market observations and 623 up-market observations (no domestic markets in our sample experienced positive returns in quarters 2 and 3 of 2002). Matched samples are created with replacement using the matching options "caliper (0.01) trim(1) common." The following set of variables is used as explanatory variables of derivatives usage: Z-score, leverage, quick ratio, size, multiple share classes, stock options, gross exchange rate exposure, foreign debt, and industry and country dummy variables. All variables are defined in Table 3.

\begin{tabular}{|c|c|c|c|}
\hline \multirow{2}{*}{ Variable } & \multicolumn{2}{|c|}{$\begin{array}{c}\text { Domestic } \\
\text { Stock Market }\end{array}$} & \multirow[b]{2}{*}{$\underline{\text { Difference }}$} \\
\hline & Down & Up & \\
\hline $\begin{array}{l}\text { Market Beta } \\
p \text {-value }\end{array}$ & $\begin{array}{r}-0.074 \\
<0.001\end{array}$ & $\begin{array}{r}-0.031 \\
0.171\end{array}$ & $\begin{array}{r}-0.044 \\
0.014\end{array}$ \\
\hline $\begin{array}{l}\text { Alpha (annualized) } \\
\text { p-value }\end{array}$ & $\begin{array}{l}0.073 \\
0.055\end{array}$ & $\begin{array}{l}0.014 \\
0.787\end{array}$ & $\begin{array}{l}0.059 \\
0.134\end{array}$ \\
\hline
\end{tabular}

Taken together, these results have important implications. First, since the adjusted-risk measures for firms that use derivatives are lower throughout the sample period, it is unlikely that the results for 2000-2001 are unique to those years. Second, and more interestingly, the evidence suggests the possibility that 
derivative use primarily lowers downside risk. ${ }^{30}$ Third, if part of the risk reduction from derivative use comes from limiting exposure to financial or economic downturns, this provides a direct mechanism for understanding why derivative use affects market value. Specifically, if derivative use lowers a firm's business-cycle risk, this may lead to a lower market beta, a lower discount rate, and therefore a higher firm value.

\section{Conclusion}

In this paper, we use a large sample of firms operating in 47 countries to analyze the effect of derivative use on measures of risk and value. In univariate tests, we find that derivative use is more prevalent in firms with higher exposures to interest rate risk, exchange rate risk, and commodity prices. Despite higher exposures, firms that use derivatives have lower estimated values of both total and systematic risk, suggesting that derivatives are used to hedge risk, rather than to speculate. There are significant differences between derivative users and nonusers along other dimensions, emphasizing the importance of multivariate tests.

Our primary multivariate test uses propensity score matching, in which derivative users and nonusers are matched on the basis of their (estimated) propensity to use derivatives. In robustness checks, we employ 2 other types of multivariate tests. Using each method, we find that compared to firms that do not use derivatives, derivative users have lower cash flow volatility, idiosyncratic volatility, and systematic risk; these results are robust to a number of different matching specifications, and the differences are both statistically and economically significant. This suggests that nonfinancial firms overall employ derivatives with the motive and effect of risk reduction. Consistent with the evidence in Allayannis and Weston (2001), derivative use is associated with a value premium, although the statistical significance of this premium is weak.

We also estimate the potential importance of selection bias on the inferences drawn from our tests, by estimating bounds beyond which the inferences would change. These results suggest that the estimated effects of derivative use on risk measures are robust: While we cannot rule out the possibility that selection bias is driving our results, any omitted control variable would have to be quite significant in its effect on risk to overturn the inference that the risk of firms that use derivatives is lower. In contrast, the value effects of derivative use are quite sensitive to selection bias. This result may explain the differences in inferences in the literature; even small differences in sample construction, control variables, and testing method could change the estimated effect.

Finally, we document that the reductions in risk we find are unlikely to be specific to our primary sample period; however, we do find that market betas vary

\footnotetext{
${ }^{30}$ Interestingly, it appears to be downside risk, and not total financial risk, that is lower for firms that use derivatives. In a separate analysis, we examined the difference in the Altman's Z-scores of derivative users and matching nonusers for surviving firms in the 4 years after a firm was classified as a "user" or "nonuser" (in 2000 or 2001). We find that derivative users have a significantly lower Z-score in every year from 2002 to 2005 . This suggests that firms that use derivatives typically have higher financial risk. We thank the referee for this suggestion; these results are available from the authors.
} 
in a way that is consistent with firms hedging downside risk. Lower betas may indicate that hedging has an effect on a firm's cost of capital and thus the investment policy and economic profitability of a firm. This in turn may explain why some of our evidence indicates that users have higher values and risk-adjusted market returns.

In further analyses, we explore whether firms' access to derivative markets, or type of derivative use, influences the effects of derivatives on firms' risk and value. We find relatively little evidence that the effects of derivatives vary across these measures. Although this may suggest that proposed new derivative rules will not prevent firms from capturing the benefits of risk management, our results should be interpreted with caution. In our judgment, the cross-sectional differences in derivative type and access in our sample are too small, and the estimates of the benefits of derivative use on risk are too large, to make that claim with this evidence.

\section{References}

Alkeback, P., and N. Hagelin. "Derivative Usage by Nonfinancial Firms in Sweden with an International Comparison.” Journal of International Financial Management and Accounting, 10 (1999), $105-120$.

Allayannis, Y., and E. Ofek. "Exchange Rate Exposure, Hedging, and the Use of Foreign Currency Derivatives.” Journal of International Money and Finance, 20 (2001), 273-296.

Allayannis, Y., and J. P. Weston. "The Use of Foreign Currency Derivatives and Firm Market Value." Review of Financial Studies, 14 (2001), 243-276.

Altman, E. I. "Financial Ratios, Discriminant Analysis and the Prediction of Corporate Bankruptcy." Journal of Finance, 4 (1968), 589-609.

Aretz, K., and S. M. Bartram. "Corporate Hedging and Shareholder Value." Journal of Financial Research, 33 (2010), 317-371.

Bank for International Settlements. "Triennial Central Bank Survey of Foreign Exchange and Derivatives Market Activity in 2004” (2005).

Bartram, S. M. “Corporate Risk Management as a Lever for Shareholder Value Creation.” Financial Markets, Institutions and Instruments, 9 (2000), 279-324.

Bartram, S. M.; G. W. Brown; and F. R. Fehle. "International Evidence on Financial Derivatives Usage." Financial Management, 38 (2009), 185-206.

Bartram, S. M.; G. W. Brown; and R. M. Stulz. "Why Are U.S. Stocks More Volatile?" Journal of Finance, forthcoming (2011).

Berkman, H.; M. E. Bradbury; and S. Magan. "An International Comparison of Derivatives Use." Financial Management, 26 (1997), 69-73.

Bodnar, G. M.; A. de Jong; and V. Macrae. "The Impact of Institutional Differences on Derivatives Usage: A Comparative Study of U.S. and Dutch Firms.” European Financial Management, 9 (2003), 271-297.

Bodnar, G. M., and G. Gebhardt. "Derivatives Usage in Risk Management by U.S. and German NonFinancial Firms: A Comparative Survey." Journal of International Financial Management and Accounting, 10 (1999), 153-187.

Bodnar, G. M.; G. S. Hayt; and R. C. Marston. "1995 Wharton Survey of Derivatives Usage by U.S. Non-Financial Firms.” Financial Management, 25 (1996), 113-133.

Bodnar, G. M.; G. S. Hayt; and R. C. Marston. "1998 Wharton Survey of Financial Risk Management by U.S. Non-Financial Firms.” Financial Management, 27 (1998), 70-91.

Bodnar, G. M.; G. S. Hayt; R. C. Marston; and C. W. Smithson. "Wharton Survey of Derivatives Usage by U.S. Non-Financial Firms.” Financial Management, 24 (1995), 104-114.

Brown, G. W.; P. R. Crabb; and D. Haushalter. "Are Firms Successful at Selective Hedging?” Journal of Business, 79 (2006), 2925-2949.

DeCeuster, M. J. K.; E. Durinck; E. Laveren; and J. Lodewyckx. "A Survey into the Use of Derivatives by Large Non-Financial Firms Operating in Belgium.” European Financial Management, 6 (2000), 301-318.

DeMarzo, P. M., and D. Duffie. "Corporate Incentives for Hedging and Hedge Accounting.” Review of Financial Studies, 8 (1995), 743-771. 
DiPrete, T. A., and M. Gangl. "Assessing Bias in the Estimation of Causal Effects: Rosenbaum Bounds on Matching Estimators and Instrumental Variables Estimation with Imperfect Instruments." Sociological Methodology, 34 (2004), 271-310.

Downie, D.; J. McMillan; and E. Nosal. "The University of Waterloo Survey of Canadian Derivatives Use and Hedging Activities.” In Managing Financial Risk, Yearbook 1996, C. W. Smithson, ed. New York: CIBC-Wood Grundy (1996).

Froot, K. A.; D. S. Scharfstein; and J. C. Stein. "Risk Management: Coordinating Corporate Investment and Financing Policies.” Journal of Finance, 48 (1993), 1629-1658.

Géczy, C.; B. A. Minton; and C. Schrand. "Why Firms Use Currency Derivatives." Journal of Finance, 52 (1997), 1323-1354.

Graham, J. R., and D. A. Rogers. "Do Firms Hedge in Response to Tax Incentives?" Journal of Finance, 57 (2002), 815-839.

Graham, J. R., and C. W. Smith, Jr. "Tax Incentives to Hedge.” Journal of Finance, 54 (1999), 22412262.

Grant, K., and A. P. Marshall. "Large UK Companies and Derivatives.” European Financial Management, 3 (1997), 191-208.

Guay, W. R. "The Impact of Derivatives on Firm Risk: An Empirical Examination of New Derivative Users." Journal of Accounting and Economics, 26 (1999), 319-351.

Guay, W., and S. P. Kothari. "How Much Do Firms Hedge with Derivatives?" Journal of Financial Economics, 70 (2003), 423-461.

Haushalter, G. D. "Financing Policy, Basis Risk, and Corporate Hedging: Evidence from Oil and Gas Producers." Journal of Finance, 55 (2000), 107-152.

Heckman, J. J. "Sample Selection as a Specification Error.” Econometrica, 47 (1979), 153-161.

Hentschel, L., and S. P. Kothari. "Are Corporations Reducing or Taking Risks with Derivatives?" Journal of Financial and Quantitative Analysis, 36 (2001), 93-118.

Jin, Y., and P. Jorion. "Firm Value and Hedging: Evidence from U.S. Oil and Gas Producers." Journal of Finance, 61 (2006), 893-919.

Koski, J. L., and J. Pontiff. "How Are Derivatives Used? Evidence from the Mutual Fund Industry." Journal of Finance, 54 (1999), 791-816.

Leland, H. E. "Agency Costs, Risk Management, and Capital Structure." Journal of Finance, 53 (1998), 1213-1243.

Loderer, C., and K. Pichler. "Firms, Do You Know Your Currency Risk Exposure? Survey Results." Journal of Empirical Finance, 7 (2000), 317-344.

Mian, S. L. "Evidence on Corporate Hedging Policy." Journal of Financial and Quantitative Analysis, 31 (1996), 419-439.

Modigliani, F., and M. H. Miller. "The Cost of Capital, Corporation Finance, and the Theory of Investment." American Economic Review, 48 (1958), 261-297.

Nance, D. R.; C. W. Smith, Jr.; and C. W. Smithson. "On the Determinants of Corporate Hedging." Journal of Finance, 48 (1993), 267-284.

Newey, W. K., and K. D. West. "A Simple, Positive Semi-Definite, Heteroskedasticity and Autocorrelation Consistent Covariance Matrix.” Econometrica, 55 (1987), 703-708.

Rosenbaum, P. R. Observational Studies, 2nd ed. New York, NY: Springer-Verlag (2002).

Rosenbaum, P. R., and D. B. Rubin. "The Central Role of the Propensity Score in Observational Studies for Causal Effects.” Biometrika, 70 (1983), 41-55.

Rountree, B.; J. P. Weston; and G. Allayannis. "Do Investors Value Smooth Performance?" Journal of Financial Economics, 90 (2008), 237-251.

Sheedy, E. "Corporate Use of Derivatives in Hong Kong and Singapore: A Survey." Working Paper, Macquarie University (2002).

Smith, C. W., and R. M. Stulz. "The Determinants of Firms' Hedging Policies." Journal of Financial and Quantitative Analysis, 20 (1985), 391-405.

Stulz, R. M. “Optimal Hedging Policies.” Journal of Financial and Quantitative Analysis, 19 (1984), 127-140.

Tufano, P. "Who Manages Risk? An Empirical Examination of the Risk Management Practices in the Gold Mining Industry." Journal of Finance, 51 (1996), 1097-1137.

Zhao, Z. "Using Matching to Estimate Treatment Effects: Data Requirements, Matching Metrics, and Monte Carlo Evidence." Review of Economics and Statistics, 86 (2004), 91-107. 